\title{
O vulcanismo alta-sílica da região do Tupanci, NW do Escudo Sul-Rio-Gran- dense: faciologia, petrografia e litoquímica
}

\author{
Felipe Padilha LEITZKE ${ }^{1}$, Carlos Augusto SOMMER², Evandro Fernandes de LIMA² \& Vinicius \\ MATTÉ $^{1}$ \\ ${ }^{1}$ Programa de Pós-graduação em Geociências, Instituto de Geociências, Universidade Federal do Rio Grande do Sul. Av. Bento \\ Gonçalves, 9500, CEP 91.540-000, Porto Alegre, RS, Brasil. E-mail: felipeplgeo@gmail.com, vinimatte@msn.com. \\ ${ }^{2}$ Instituto de Geociências, Universidade Federal do Rio Grande do Sul. Av. Bento Gonçalves, 9500, CEP 91.540-000, Porto Alegre, \\ RS, Brasil. E-mail: casommer@sinos.net, evandro.lima@ufrgs.br.
}

Recebido em 05/09/2013. Aceito para publicação em 13/03/2015.

Versão online publicada em 30/04/2015 (www.pesquisasemgeociencias.ufrgs.br)

\begin{abstract}
Resumo - A região do Tupanci, noroeste do Escudo Sul-Rio-Grandense (ESRG), apresenta depósitos vulcânicos ácidos, estratigraficamente correlacionados à Formação Acampamento Velho ( $\sim 550$ Ma), da Bacia do Camaquã. Esta região é a exposição mais setentrional deste episódio vulcânico, caracterizado por sequências efusivas e piroclásticas, dominantemente ácidas, afinidade alcalina alta sílica sódica e vinculadas ao magmatismo pós-colisional do ciclo orogênico Brasiliano/Pan-Africano no ESRG. As vulcânicas ácidas ocorrem na forma de depósitos efusivos e, em menor volume, piroclásticos, distribuídas em dois cerros: Cerro Tupanci e Cerro dos Picados. 0 Cerro Tupanci é uma intrusão subvulcânica alongada N-S, representada por riolitos porfiríticos, com fenocristais de sanidina e quartzo e uma matriz quartzo-feldspática equigranular fina a afanítica, com intensa foliação de fluxo nas regiões de borda. No Cerro dos Picados ocorrem riolitos texturalmente semelhantes, porém com matriz afanítica de aspecto vítreo e presença de biotita, além de depósitos piroclásticos de ignimbritos riolíticos, divididos em duas fácies: uma rica em líticos, com púmices devitrificados e pouco estirados, além de pequenos e raros cristaloclastos; e outra de ignimbritos reomórficos, com abundantes púmices devitrificados, destacada textura eutaxítica, mais rica em cristaloclastos e raros litoclastos. 0 comportamento geoquímico de ambas as fácies classifica o magmatismo como supersaturado em sílica, semelhante aos sistemas de alta sílica, afinidade alcalina sódica, e tendência metaluminosa a levemente peralcalina, com características dos granitos tipo "A". Os dados faciológicos, petrográficos e litoquímicos obtidos indicam vinculação genética destas rochas com o vulcanismo da Formação Acampamento Velho.
\end{abstract}

Palavras-chave: Vulcanismo, Formação Acampamento Velho, Bacia do Camaquã, Tupanci.

\begin{abstract}
High-Silica volCanism of the Tupanci Region, NoRTHWESTERn PORTION OF THE Sul-RIO-GRANDENSE SHIELD: FACIOLOGY, PETROGRAPHY AND LITHOCHEMISTRY. Volcanic and hypabyssal acid rocks occur in the Tupanci area, NW portion of the Sul-Rio-Grandense Shield. These rocks are stratigraphically correlated to the Acampamento Velho Formation ( 550 Ma), at the Camaquã Ba$\sin$. This region has the northernmost exposure of this volcanic episode, which comprises effusive/ hypabyssal and pyroclastic rocks, with dominantly acid composition and sodic-alkaline affinity, whose genetic processes are linked to the post-collisional stages of the Brasiliano/Pan-Africano orogenic cycle. Acid volcanic rocks occur mainly as effusive deposits and also as pyroclastic deposits, in two Cerros (Hills): Tupanci and Picados. Cerro Tupanci defines an elongated (N-S) sub-volcanic intrusion of porphyritic rhyolites with phenocrysts of alkali feldspar and quartz surrounded by equigranular-fine-grained to aphanitic quartz-feldspar matrix, with a strong flow foliation on border regions. Cerro dos Picados shows texturally similar rhyolites, but with aphanitic to glassy matrix and presence of biotite; and pyroclastic deposits, characterized by rhyolitic ignimbrites. Ignimbrites occur in two facies: lithic-rich, with few devitrified and poorly elongated pumice and crystal fragments; and rheomorphic, with abundance of devitrified pumices with detachable eutaxitic texture, crystal fragments and rarely lithic fragments. Geochemical behavior allows to classify the magmatism as silica oversaturated, similar to the systems with high-silica, alkaline affinity and a metaluminous to slightly peralkaline trend with similar characteristics to "A" type granites. Petrographic and lithochemical data indicate a genetic linkage with the Acampamento Velho Formation magmatism.
\end{abstract}

Keywords: Volcanism, Acampamento Velho Formation, Camaquã Basin, Tupanci. 


\section{Introdução}

Na região do Tupanci, localizada na porção noroeste do Escudo Sul-Rio-Grandense (ESRG), domínio São Gabriel (Chemale Jr., 2000; Hartmann et al., 2007), aflora um expressivo volume de depósitos vulcânicos e hipabissais de composição ácida da Formação Acampamento Velho, uma das unidades da Bacia do Camaquã (e.g., Wildner et al., 2002; Sommer et al., 2005a; Lima et al., 2007).

Os ciclos vulcânicos nesta bacia foram estabelecidos dominantemente sob condições subaéreas e foram descritos por Wildner et al. (2002) e Lima et al. (2007). 0 ciclo vulcânico mais antigo, com composições dominantemente intermediárias e algumas ocorrências básicas e ácidas, possui afinidade shoshonítica (Formação Hilário sensu Ribeiro \& Fantinel, 1978) e é sucedido por um vulcanismo bimodal de afinidade moderadamente alcalina sódica (Formação Acampamento Velho sensu Ribeiro \& Fantinel, op. cit.), reunindo depósitos explosivos/efusivos de composição ácida e básica. O último registro de rochas vulcânicas na Bacia do Camaquã é caracterizado por rochas efusivas de composição básica-intermediária e afinidade moderadamente alcalina a toleítica alto- $\mathrm{K}$, estratigraficamente vinculadas à Formação Guaritas e definido como Membro Rodeio Velho (Ribeiro \& Fantinel, op. cit. ).

Estes ciclos vulcânicos são relacionados à transição entre o período colisional e pós-colisional, desenvolvidos entre o Neoproterozoico III e o Cambriano Inferior. A fonte deste magmatismo é atribuída a fusões parciais do manto litosférico modificado por uma subducção prévia (Nardi \& Bonin, 1991; Wildner et al., 1999, 2002; Nardi \& Lima, 2000; Almeida et al., 2005; Sommer et al., 2005a, 2005b, 2006) que, segundo estes autores, representariam partes preservadas de uma sequência evolutiva típica de um magmatismo pós-colisional (sensu Liégeois, 1998), onde magmas shoshoníticos estão presentes nas fases iniciais, tipicamente relacionados a fontes afetadas por subducção, sucedidos por sequências vulcânicas bimodais de afinidade alcalina sódica e saturadas em sílica e finalmente toleíticas.

A Formação Acampamento Velho, na qual se insere o objeto deste artigo, representa a fração vulcânica do magmatismo alcalino sódico, supersaturado em sílica, sem registros de deformação e metamorfismo e de caráter bimodal, representado por um expressivo volume de depósitos efusivos e piroclásticos de composição ácida, associados às lavas e diques de composição básica (Sommer et al., 1999, 2003, 2005a, 2006; Wildner et al., 1999,
2002; Almeida et al., 2002; Lima et al., 2007). Dados geocronológicos recentes forneceram idades entre 549 e 573 Ma para as rochas vulcânicas desta unidade (Sommer et al., 2005b; Janikian et al., 2008). A organização estratigráfica desta formação tem sido sugerida por diversos autores (e.g., Porcher et al., 1995; Sommer et al., 1999, 2005b, 2006; Wildner et al., 1999, 2002; Zerfass et al., 2000; Fragoso-César et al., 2000, 2003; Almeida et al., 2002; Janikian et al., 2008, 2012), sendo que as melhores exposições localizam-se no Platô da Ramada (Vila Nova do Sul), no Platô do Taquarembó (região de Dom Pedrito) e nos cerros do Bugio e Perau (Serra de Santa Bárbara, região de Caçapava do Sul), além das exposições na região do Tupanci, mais setentrionais destes episódios vulcânicos no ESRG. Trabalhos específicos sobre estes depósitos são escassos, destacando-se as descrições apresentadas por Menegotto \& Medeiros (1976) e Roisenberg et al. (1986).

No presente trabalho são descritos e interpretados a faciologia vulcânica dos depósitos na região do Tupanci, seus aspectos petrográficos e litoquímicos, e os vínculos estratigráficos com a Formação Acampamento Velho da Bacia do Camaquã.

\section{2 Área, materiais e métodos}

\subsection{Contexto geológico regional}

O Escudo Sul-Rio-Grandense (ESRG) corresponde à porção meridional da Província Mantiqueira no Estado do Rio Grande do Sul (Almeida et al., 1981), e está composto por rochas relacionadas ao ciclo orogênico neoproterozoico Brasiliano/Pan-Africano, com um embasamento metamórfico de idade paleoproterozoica, constituído por fragmentos remanescentes do Cráton Rio de La Plata (Hartmann et al., 2000, 2007; Soliani Jr. et al., 2000). Estas rochas podem ser divididas em quatro terrenos: Taquarembó (complexo granulítico paleoproterozoico retrabalhado parcialmente no Neoproterozoico), São Gabriel (assinatura juvenil, com associações petrotectônicas de ambientes de margem passiva e de retro-arco, ofiolitos, arcos magmáticos vulcano-sedimentares e plutônicos derivados de um manto neoproterozoico), Tijucas (rochas paleoproterozoicas gnáissicas de composição tonalítica a diorítica e neoproterozoicas, metavulcânicas e metassedimentares resultantes da deposição em crosta continental distendida ou de um arco magmático continental, com retrabalhamento de crosta continental paleoproterozoica) e 
Pelotas (complexo granítico e suítes intrusivas de idade brasiliana, entre 650-550 Ma, relacionadas à atuação de zonas de cisalhamento) (Jost \& Hartmann, 1984; Soliani Jr., 1986; Chemale Jr., 2000; Hartmann et al., 2000, 2007; Phillipp \& Machado, 2005; Phillipp et al., 2007). Dentre os domínios do ESRG, no Terreno São Gabriel estão depositadas importantes sequências vulcânicas vinculadas ao magmatismo nos estágios pós-colisionais do ciclo orogênico Brasiliano, como o Platô da Ramada e a região do Tupanci, inseridas na Formação Acampamento Velho, da Bacia do Camaquã.

O magmatismo neoproterozoico no ESRG pode ser dividido em duas fases principais: uma desenvolvida em um ambiente típico de arco, com idades entre 850-700 Ma, e outro evento desenvolvido em um ambiente pós-colisional (sensu Liégeois, 1998), com idades entre 650-535 Ma, marcado por intenso magmatismo ao longo de zonas de cisalhamento transcorrentes (Fernandes et al., 1995; Babinski et al., 1997; Bitencourt \& Nardi, 2000; Chemale Jr., 2000; Hartmann et al., 2000, 2007; Nardi \& Bitencourt, 2009).

A Bacia do Camaquã (Fig. 1) agrupa um conjunto expressivo de unidades sedimentares e vulcanogênicas, sem indícios de metamorfismo regional, depositadas aproximadamente entre $620 \mathrm{e}$ 535 Ma por cerca de $150 \mathrm{~km}$ na direção E-W, entre Encruzilhada do Sul e São Gabriel, e cerca de 120 km na direção N-S, entre São Sepé e Bagé (Paim et al., 2000; Borba, 2006; Janikian et al., 2008; Almeida et al., 2010). 0 embasamento sobre o qual estas sequências se depositaram é heterogêneo, variando desde complexos granulíticos paleoproterozoicos até terrenos brasilianos, representados por associações de rochas ígneas e metamórficas (Paim et al., 2000; Lima et al., 2007).

A evolução desta bacia é caracterizada por uma alternância entre intervalos em que predominam eventos deposicionais, com o acúmulo de espessos pacotes sedimentares e vulcano-sedimentares e intervalos predominantemente erosionais. Durante o intervalo deposicional formaram-se os depósitos vulcânicos alternados com sedimentação siliciclástica. A sequência sedimentar da Bacia do Camaquã registra uma evolução da deposição, desde marinho raso, passando por lacustre-aluvial, até de ambientes desérticos continentais (Paim et al., 2000), representada, da base para o topo, pela Formação Maricá, com depósitos dominantemente costeiros e marinhos, Grupo Bom Jardim, com depósitos aluviais intercalados a andesitos, vulcânicas efusivas e piroclásticas ácidas (Formações Hilário e Acampamento Velho) e depósitos continentais fluviais, lacustres e eólicos (Grupo Camaquã, Formações Santa Bárbara e Guaritas) (Borba et al., 2007).

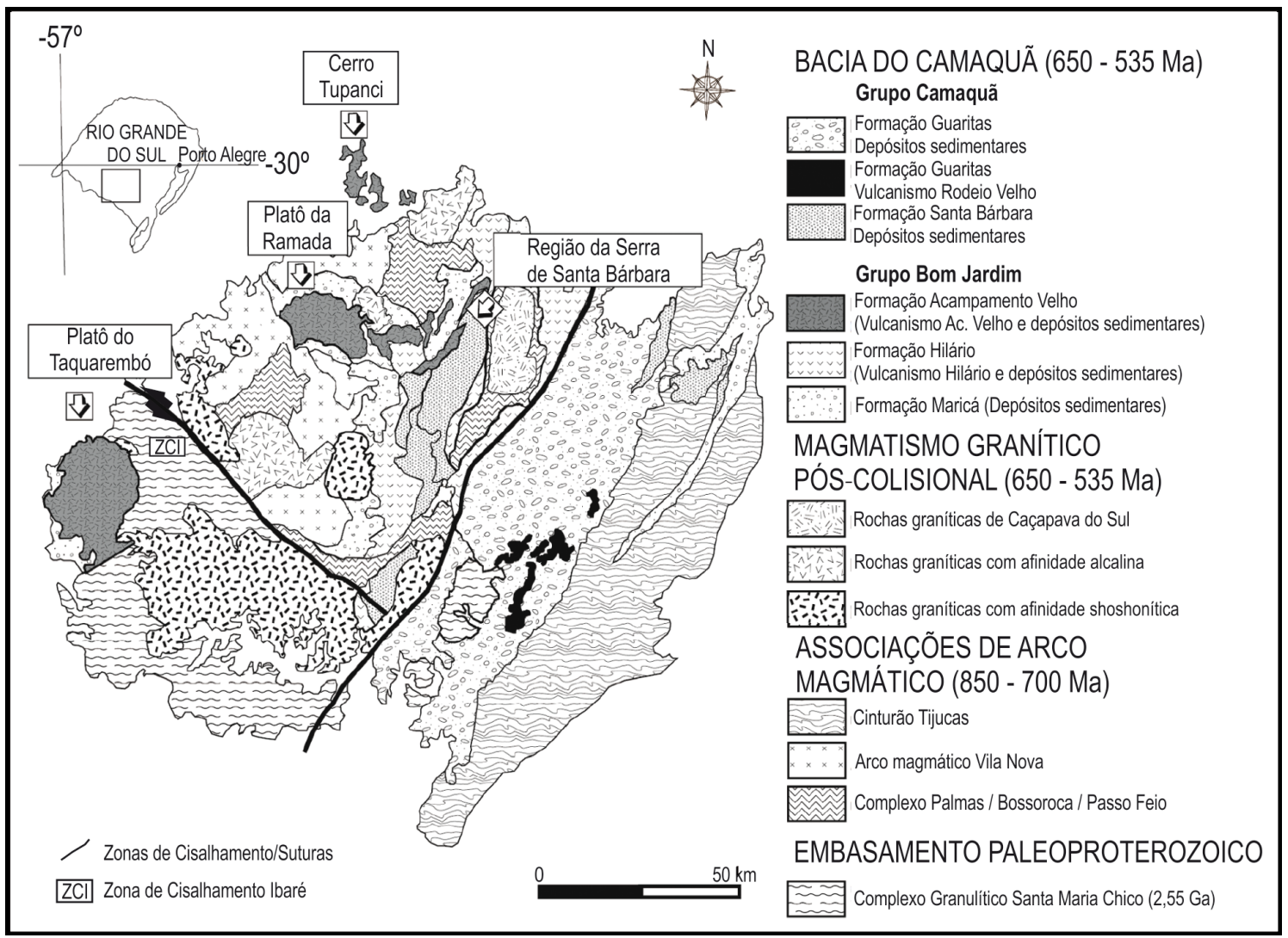

Figura 1. Esboço geológico do ESRG, com a distribuição das principais ocorrências do vulcanismo Neoproterozoico na bacia do Camaquã (modificado de Lima et al., 2007). 
Este conjunto de unidades teve seu desenvolvimento dominantemente em um ambiente continental, sob condições subaéreas (Wildner et al., 2002), considerada como do tipo strike-slip, embora seus mecanismos de geração e classificação ainda sejam discutidos por diversos autores (e.g., Brito Neves \& Cordani, 1991; Gresse et al., 1996; Brito Neves et al., 1999; Chemale Jr., 2000; Paim et al., 2000; Fragoso-César et al., 2000, 2003; Sommer et al., 2006; Janikian et al., 2008, 2012).

\subsection{Métodos}

Para a obtenção dos dados litoquímicos foram selecionadas 19 amostras representativas da ampla distribuição espacial e composicional dos vulcanitos. Quatorze amostras foram analisadas no Acme Analytical Laboratories Ltd., utilizando a técnica ICP (Inductively Coupled Plasma) para elementos maiores e ICP-MS (Inductively Coupled Plasma Mass Spectrometry) para elementos traço e terras raras (ETR), e 5 amostras foram analisadas para elementos maiores e alguns traços no Laboratório de Geoquímica do Centro de Pesquisa em Geoquímica da Universidade Federal do Rio Grande do Sul. Nestas últimas utilizou-se o método da espectrometria de fluorescência de raios-X. Os dados obtidos foram organizados e tratados estatisticamente nos programas Microsoft Excel 2007 e Geochemical Data Toolkit 2.3.

\section{Resultados e discussão}

\subsection{Geologia da região do Tupanci}

A região do Tupanci localiza-se cerca de 15 $\mathrm{km}$ ao norte do município de Vila Nova do Sul e é caracterizada pela ocorrência de unidades do ESRG na forma de uma "janela do embasamento soerguido", cercadas por unidades da Bacia do Paraná (Fig. 2). Expressivos volumes de rochas vulcânicas ácidas, relacionadas estratigraficamente à Formação Acampamento Velho, ocorrem em duas feições geomorfológicas de destaque: o Cerro Tupanci, caracterizado por rochas riolíticas com características hipabissais e o Cerro dos Picados, com derrames e ignimbritos riolíticos.

o Complexo Cambaí, unidade mais antiga presente na área, é representado por gnaisses dioríticos a tonalíticos com idades entre 735-680 Ma (Babinski et al., 1996; Hartmann et al., 2007, 2011), cortados pelos riolitos da Formação Acampamento Velho e pelos lamprófiros espessartíticos da Formação Hilário. A Formação Maricá, base da
Bacia do Camaquã, é caracterizada principalmente por siltitos basculados e cataclasados, além de arenitos arcoseanos. Estas rochas apresentam melhores exposições na porção oeste do Cerro Tupanci, intrudidas por rochas vulcânicas das formações Acampamento Velho e Hilário (Fig. 2). Segundo Borba (2006), a Formação Maricá é caracterizada por arenitos fluviais de composição arcoseana a subarcoseana na base; sedimentação marinha na porção intermediária, com predominância de siltitos e folhelhos esverdeados e arenitos de composição arcoseana lítica, com presença de fragmentos vulcânicos. No topo da sequência, predominam rochas sedimentares de origem fluvial, com arenitos e conglomerados com fragmentos vulcânicos. A idade deposicional desta sequência situa-se aproximadamente entre 620 e 592 Ma (Paim et al., 2000).

A Formação Hilário (Ribeiro \& Fantinel, 1978), pertencente ao Grupo Bom Jardim (Ribeiro et al., 1966), é o primeiro episódio vulcânico com registros expressivos na Bacia do Camaquã. Este magmatismo é caracterizado por rochas vulcânicas e hipabissais de afinidade shoshonítica, apresentando uma variação composicional desde termos básicos a ácidos. Esta unidade é representada por andesitos e lamprófiros que se concentram ao norte do Cerro Tupanci, em corpos isolados (Fig. 2). Os lamprófiros foram descritos em detalhe por Buckowski et al. (2010), como diques com direção $\mathrm{N}-\mathrm{NE}$, de espessura métrica e apresentam uma mineralogia espessartítica. Além destas unidades litológicas da Formação Hilário, também ocorrem conglomerados vulcanogênicos com clastos de andesitos e lamprófiros, e feições de interação sedimento-lava, com a geração de peperitos, aflorantes a oeste do Cerro Tupanci (Fig. 2).

As rochas associadas estratigraficamente à Formação Acampamento Velho ocorrem como intrusões rasas, derrames e depósitos piroclásticos. As sequências hipabissais afloram no Cerro Tupanci, enquanto as ocorrências vulcânicas efusivas e piroclásticas localizam-se no Cerro dos Picados (Fig. 2). Encontram-se sobrepostas e intrudindo na forma de diques às rochas sedimentares da Formação Maricá (siltitos, ardósias e arcóseos) e vulcânicas da Formação Hilário (andesitos e lamprófiros).

As rochas mais jovens da região são sequências sedimentares da Bacia do Paraná, com arenitos ferruginosos, siltitos, folhelhos e folhelhos betuminosos. Pertencem às Formações Rio Bonito e Palermo, inseridas no Grupo Guatá (Permiano Inferior) e à Formação Irati, inserida no Grupo Passa Dois (Permiano Inferior - Santos et al., 2006). 




Figura 2. Esboço geológico da região do Tupanci (modificado de Menegotto \& Medeiros, 1976). 
O contato entre estas unidades e as unidades do ESRG na região é erosivo, ocorrendo por quebras do relevo e diferenças no padrão geomorfológico (Fig. 2).

\subsection{Faciologia e petrografia dos depósitos vulcâni- cos ácidos}

\subsubsection{Cerro Tupanci (CT)}

O Cerro Tupanci é constituído por um corpo subvulcânico alongado no sentido N-S, com dimensões de cerca de $4 \mathrm{~km} \times 0,5 \mathrm{~km}$ e um padrão de falhas no sentindo NE-SW que o segmentam em zonas descontínuas, gerando zonas de cataclase com cominuição dos grãos. Pode ser separado em uma fácies de núcleo e outra de borda. A fácies de núcleo é maciça e rica em fenocristais e a fácies de borda apresenta uma marcante foliação de fluxo ígneo e uma diminuição substancial no tamanho de grão.

\subsubsection{Fácies de núcleo (Fn)}

As rochas da porção de núcleo são riolitos porfiríticos com fenocristais (30\%) euédricos a subédricos de feldspato alcalino (sanidina) e quartzo, imersos em cerca de $70 \%$ de uma matriz equigranular fina quartzo-feldspática (Fig. 3A). Os fenocristais de sanidina (Fig. 3B) são subédricos, prismáticos, por vezes alongados, e com compri- mento variando entre 1,5 e 2,5 mm. Alguns cristais apresentam macla simples, micropertitas, sendo comum uma forte argilização/oxidação como processo secundário. Os fenocristais de quartzo são euédricos a subédricos, com diâmetro variando de 1,0 a 2,5 mm (Fig. 3C) e mostram feições de reabsorção, com golfos de corrosão ou hábito arredondado (Fig. 3D). Ocorrem também como agregados, definindo uma textura glomeropofirítica. Microfenocristais de minerais opacos, zircão, apatita e máficos (anfibólios) alterados para clorita são os minerais acessórios. Os opacos foram identificados no MEV e, através da sua forma cúbica característica, classificados como pirita. Os minerais máficos são raros e estão transformados pseudomorficamente em clorita, além de pequenos $(\sim 0,05 \mathrm{~mm})$ prismas aciculares de anfibólio de cristalização tardia na matriz e minerais máficos tardios, com pleocroísmo verde-azulado, corroídos, interpretados como anfibólio sódico (arfvedsonita), sugerindo uma relação álcalis/alumina peralcalina.

A matriz é microcristalina e caracterizada pelo arranjo em mosaico de micrólitos de quartzo e feldspato alcalino. É comum a presença das texturas micrográficas (Fig. 3E) de intercrescimento entre o feldspato alcalino e o quartzo. Em algumas porções isoladas observa-se textura esferulítica (Fig. 3F), de forma esférica predominante, com esferulitos isolados ou nucleados por fenocristais, o que sugere processos de devitrificação em alta temperatura (Logfren, 1971).
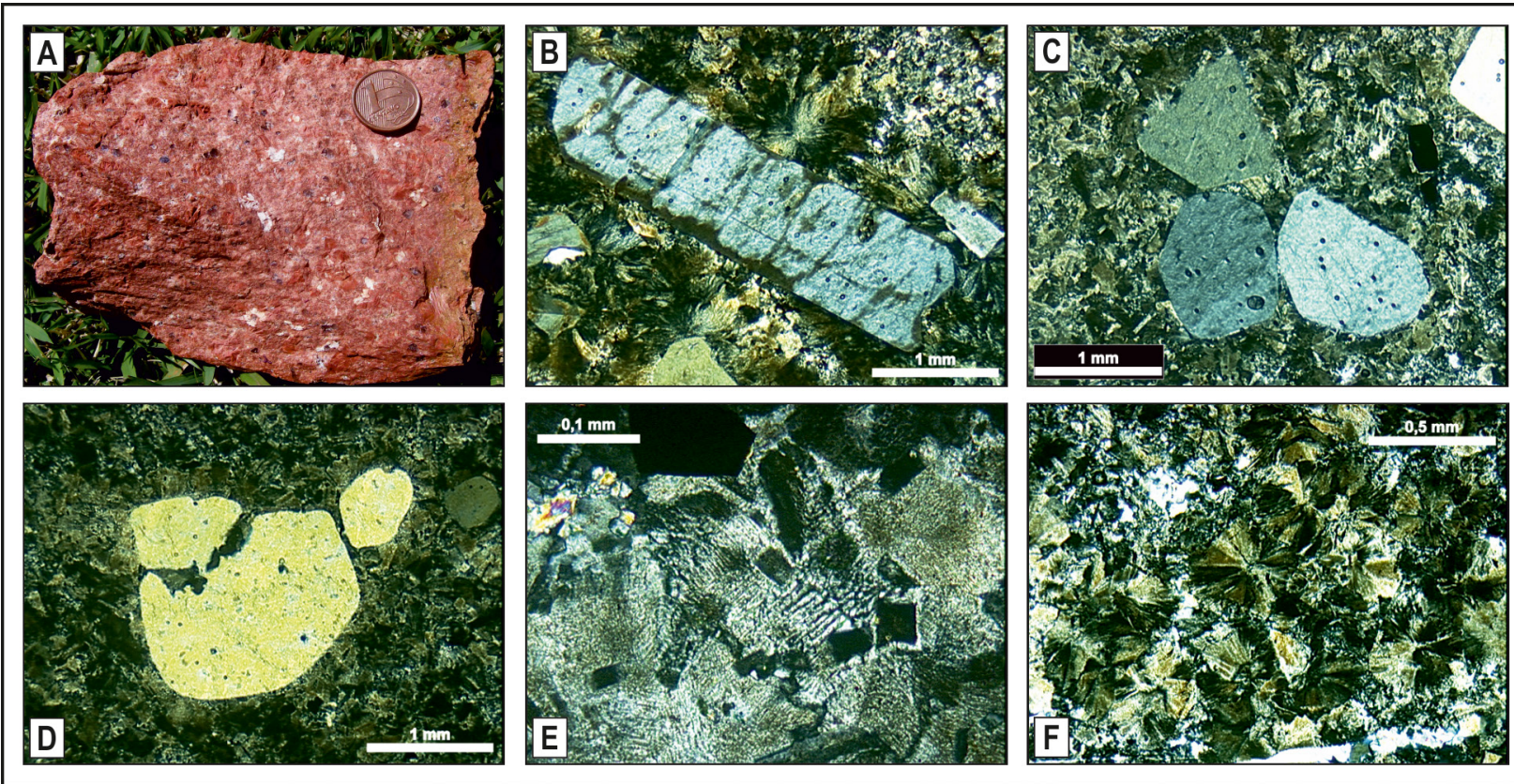

Figura 3. Aspectos petrográficos macro e microscópicos dos riolitos da FN do Cerro Tupanci: A) riolito porfirítico; B) fenocristal de sanidina (LP); C) fenocristais de quartzo em textura glomeroporfirítica (LP); D) feições de reabsorção em grãos de quartzo (LP); E) textura micrográfica de intercrescimento na matriz (LP); F) textura esferulítica de devitrificação na matriz (LP). 


\subsubsection{Fácies de borda (Fb)}

A fácies de borda possui uma composição mineralógica similar à de núcleo, porém com um menor conteúdo de fenocristais (15\%) e maior volume de matriz (85\%). A forte foliação ígnea é caracterizada pela alternância de níveis milimétricos com diferentes graus de cristalinidade, com textura microcristalina (Fig. 4AG). Na foliação de fluxo são observadas microdobras e cristais rotacionados (Fig. 4B), gerando padrões texturais tuff-like, semelhantes às texturas eutaxíticas e parataxíticas. A semelhança textural entre lavas ou intrusões rasas, como no caso da fácies de borda, com ignimbritos reomórficos, foi discutida por Manley (1995). Este autor classificou como "tuff-like rhyolites" os termos efusivos com texturas aparentemente piroclásticas. A condição original hipocristalina desta fácies é sugerida pela presença de texturas esferulítica e axiolítica, comuns em devitrificação de alta temperatura.

Os fenocristais de sanidina (Fig. 4C) e quartzo apresentam-se similares aos da porção de núcleo. O quartzo apresenta golfos de corrosão, com maior frequência, e geometria amebóide (Fig. 4D), além do menor tamanho dos cristais quando comparado a FN, sendo de $\emptyset \sim 1,0 \mathrm{~mm}$ (quartzo) e comprimento entre $0,5-1,5 \mathrm{~mm}$ (feldspato alcalino). Este fato é indicativo de um maior undercooling desta fácies, gerado pelo contato direto com a encaixante. Alguns grãos estão fraturados, cujo arranjo caracteriza microbrechas. Segundo Manley (1995) o termo "microbreccia" é utilizado para as porções da rocha onde são observados fragmentos de vidro e cristais. Esta feição é comum em sistemas riolíticos de alta viscosidade do fluxo (Fig. 4EG).

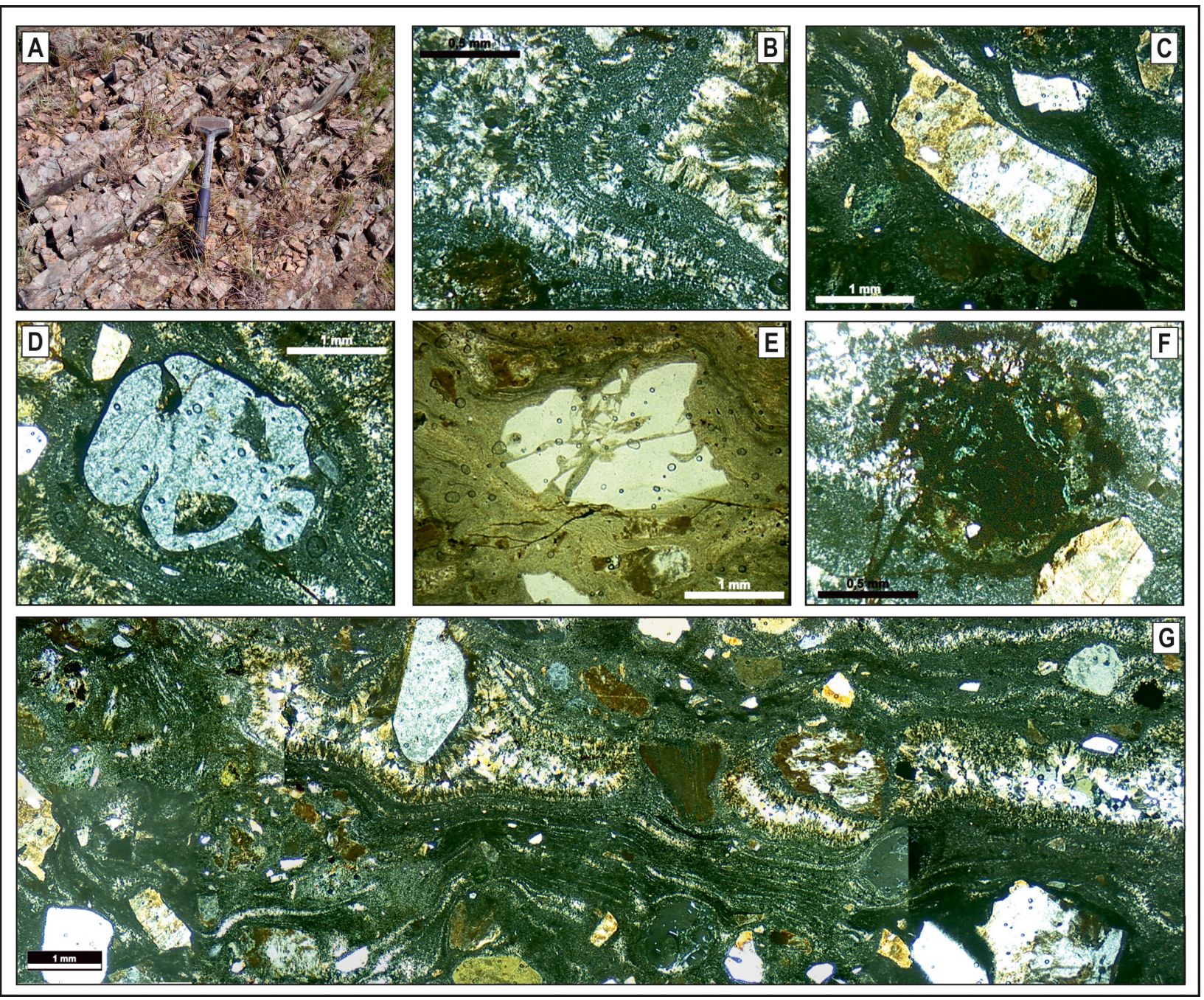

Figura 4. Aspectos petrográficos macro e microscópicos da FB do Cerro Tupanci: A) afloramento com foliação de fluxo e fraturamento intenso; B) textura axiolítica evidenciando processos de devitrificação(LP); C) fenocristal de sanidina envolto por matriz felsifírica e estrutura de fluxo (LP); D) grão de quartzo com fortes feições de reabsorção pela matriz e geometria amebóide envolto por estrutura de fluxo (LP); E) fenocristal de quartzo microbrechado (LP); F) amígdala preenchida por opacos + clorita (LP); G) fotomicrografica panorâmica da lâmina mostrando a continuidade da foliação de fluxo e os níveis com diferentes graus de cristalinidade (LP). 
Fragmentos de minerais máficos são observados pseudomorfizados para clorita. Ocorrem ainda amígdalas preenchidas por uma massa de opacos + clorita (Fig. 4F) e xenólitos de rochas encaixantes, provavelmente da Formação Maricá.

\subsubsection{Cerro dos Picados (CP)}

0 Cerro dos Picados é uma feição geomorfológica com uma área aproximada de $24 \mathrm{~km}^{2}$ que ocorre a oeste do Cerro Tupanci. É truncado por duas zonas de falhas principais, com direção preferencial NE-SW. As rochas vulcânicas tem origem efusiva e explosiva. Os derrames riolíticos são porfiríticos e concentram-se na porção centro-norte do Cerro. Os depósitos piroclásticos são caracterizados por ignimbritos riolíticos com elevado grau de soldagem. Em algumas porções predominam grãos do tamanho lapilli, com abundância em fragmentos líticos e em outras ocorrem principalmente ignimbritos reomórficos, ricos em cristais e com fragmentos piroclásticos de tamanho de grão cinza preponderante. Embora as relações estratigráficas entre as duas unidades não sejam claras em campo, a presença de fragmentos riolíticos nos ignimbritos sugere que os eventos piroclásticos estudados são posteriores aos eventos efusivos.

\subsubsection{Regime efusivo}

0 regime efusivo é caracterizado por riolitos porfiríticos com fenocristais (25\%) de quartzo e sanidina, envoltos por uma matriz afanítica $(75 \%)$ de aspecto vítreo (Fig. 5A). Observa-se foliação de fluxo com atitudes variadas e mergulho principalmente sub-horizontal, além de porções com autobrechação incipiente (Fig. 5B).

Os fenocristais de quartzo têm diâmetro entre 1 e $2 \mathrm{~mm}$, bordas corroídas e feições de reabsorção pela matriz mais intensas do que as observadas nas rochas do CT, com golfos de corrosão e geometria ameboide em alguns grãos (Fig. 5C). Os fenocristais de sanidina (Fig. 5D) possuem hábito variando de tabular a prismático, por vezes alongados, com comprimento entre 0,5 e $2 \mathrm{~mm}$. Alguns cristais encontram-se acunhados em uma das extremidades ou com feições de reação com a matriz, o que torna as bordas difusas.

Microfenocristais de minerais opacos, zircão e apatita ocorrem como acessórios. Os minerais máficos são na maior parte biotita, originada pela alteração de anfibólios e, em algumas porções, pseudomorfizados para uma massa de clorita+biotita. Os grãos de biotita são subédricos, com 0,5-1 mm de diâmetro, variando de marrom a verde e, em algumas porções, alterados em parte para clorita. Possuem apenas uma direção de clivagem e ocorrem por vezes com textura poiquilítica ou em agregados associados às cloritas, substituindo anfibólios. A matriz é muito fina e constituída por um arranjo quartzo-feldspático, microcristalino a criptocristalino (Fig. 5E). Processos de devitrificação são comuns e vários estágios são observados, desde esferulitos e axiolitos até intercrescimentos granofíricos e micrográficos (Fig. 5F).3.2.2.2 Regime explosivo
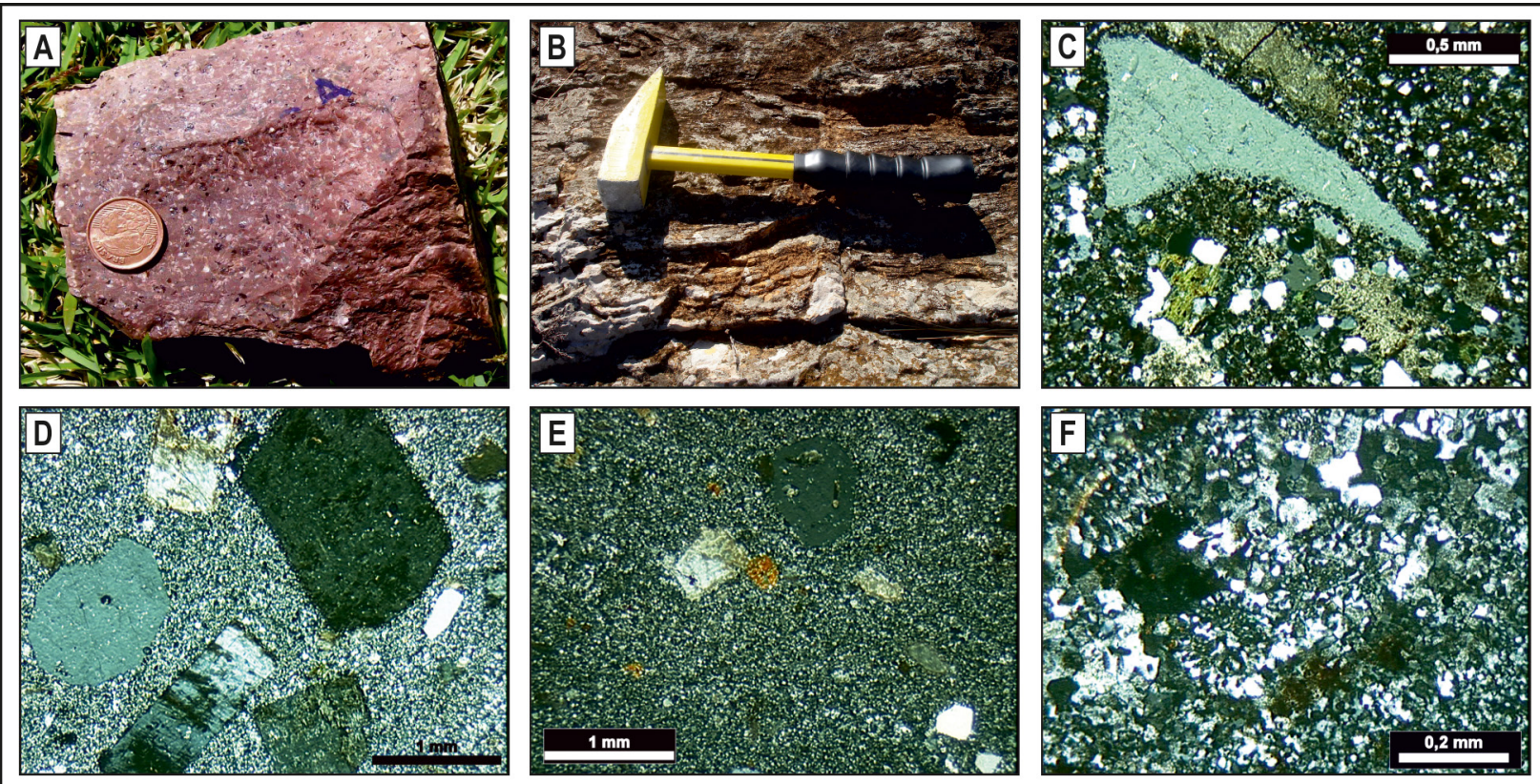

Figura 5. Aspectos petrográficos macro e microscópicos dos riolitos do Cerro dos Picados: A) riolito porfirítico com matriz de aspecto vítreo; B) foliação de fluxo com autobrechação; C) grão de quartzo com as bordas corroídas (LP); D) textura glomeroporfirítica com fenocristais euédricosde sanidina em matriz microcristalina (LP); E) matriz com arranjo microcristalino quartzo-feldspático e fenocristais de quartzo, sanidina e biotita (LP); F) textura micrográfica em matriz de riolito porfirítico (LP). 
As rochas piroclásticas são caracterizadas por ignimbritos mal selecionados, com piroclastos variando de cinza à lapilli, constituídos por litoclastos, fenocristais, fragmentos de cristais e vítreos. Os ignimbritos são fortemente soldados, de composição riolítica e podem ser separados em duas fácies: ignimbritos lapilíticos ricos em líticos ( $\operatorname{IgL}$ ) e ignimbritos reomórficos enriquecidos em cristais (IgnReo).

\section{Fácies de ignimbritos ricos em líticos (IgL)}

As rochas desta unidade são mal-selecionadas, de cor rosa acastanhada, com predomínio de lápilis (Fig. 6A) imersos em matriz tufácea. Os líticos são predominantes, constituídos por fragmentos de riolitos e ignimbritos. Em menor quantidade observam-se fragmentos de púmices e cristais (quartzo e feldspato alcalino). Em geral, os fragmentos de tamanho lapilli correspondem a cerca de $55 \%$ da rocha, enquanto a matriz tufácea corresponde a $45 \%$. Os fragmentos de púmices (Fig. 6B) variam desde cinza, confundindo-se com a matriz, até o tamanho lapilli (Fig. 6C), encontram-se completamente devitrificados para um arranjo granofírico quartzo-feldspático, formando algumas vezes textura axiolítica. 0 nível de achatamento dos púmices é baixo, observando-se uma incipiente textura eutaxítica. Os fragmentos líticos estão com as bordas corroídas, indicando assimilação, representados por rochas riolíticas e ignimbríticas juvenis (Fig. 6E). 0 processo de argilização deixa uma película marrom-avermelhada sobre os fragmentos. Os fragmentos de cristais ocorrem em menor quantidade e são representados por quartzo e raramente feldspato alcalino. Os cristais estão fraturados, angulosos, com bordas irregulares e tamanho em torno de 0,2 $\mathrm{mm}$. Além de fragmen-
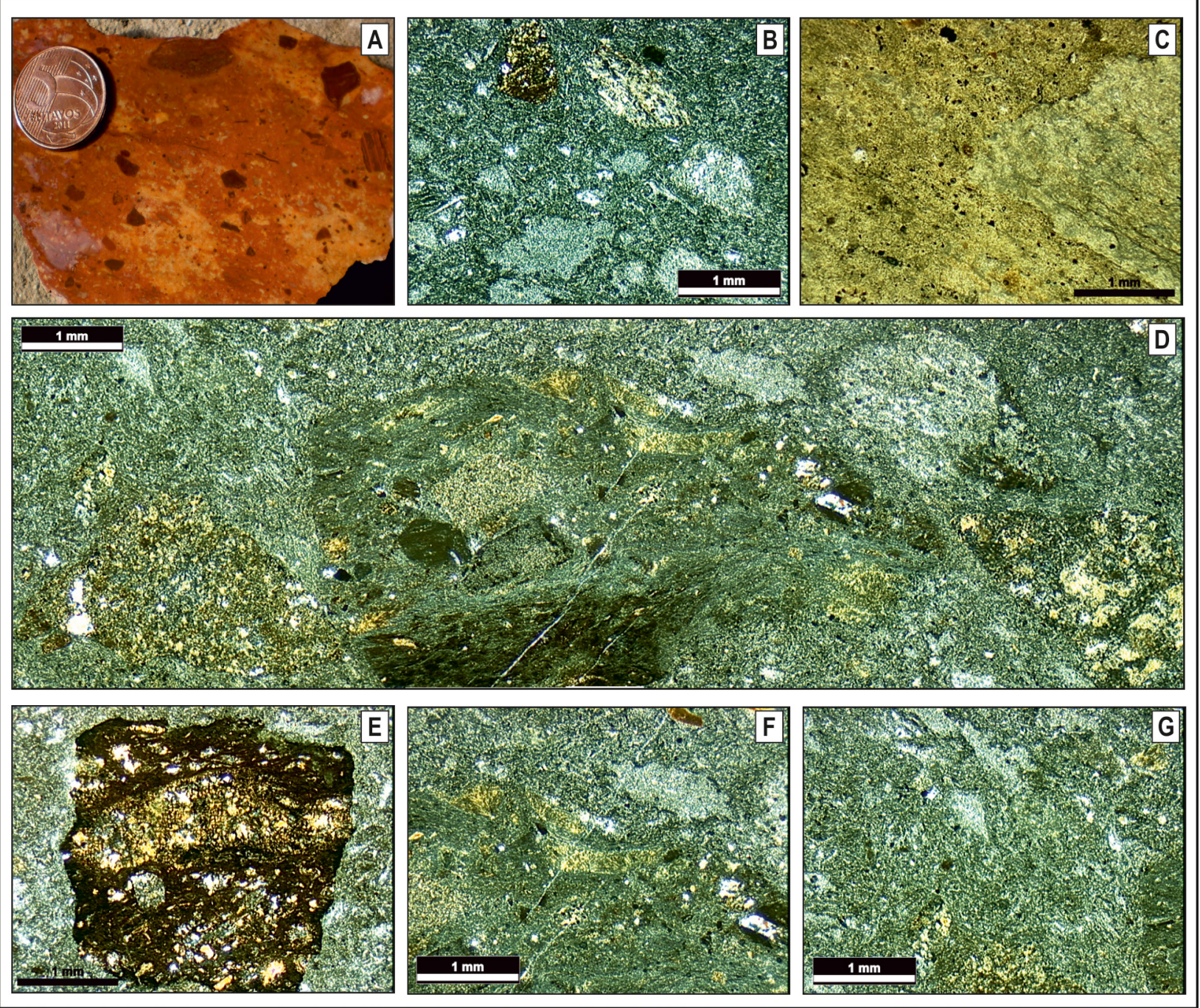

Figura 6. Aspectos petrográficos macro e microscópicos das rochas ignimbríticas da fácies rica em líticos do Cerro dos Picados: A) fragmentos piroclásticos do tamanho lapilli em amostra de mão; B) fragmentos de púmices com diversas orientações em matriz à base de shards (LP); C) fragmento de púmice cortado ortogonal a direção do escape de gases, com bordas difusas (LN); D) fotomicrografia panorâmica da lâmina mostrando os fragmentos de púmices e líticos de tamanho lapilli (LP); E) litoclasto de ignimbrito riolítico (LP); F) matriz tufácea com shards e textura axiolítica de devitrificação (LP); G) fragmentos de púmices devitrificados na matriz (LP). 
tos de cristais, destaca-se a existência de fenocristais destes mesmos minerais, de tamanho similar, subédricos a euédricos, muitos deles preservados dentro dos púmices.

A matriz é extremamente fina, a base de shar$d s$ em geometria "Y" (espícula), de comprimento menor que 0,5 mm (Fig. 6F). Observam-se também em algumas porções textura axiolítica de intercrescimento entre o quartzo e o feldspato alcalino, geralmente devido ao processo de devitrificação sobre os púmices (Fig. 6G).

Fácies de ignimbritos reomórficos (IgnReo)

Esta fácies é caracterizada por ignimbritos vinculados a elevados graus de soldagem (Fig. 7A), caracterizada por grande quantidade de cristais (fenocristais e fragmentos) e matriz fina, de aspecto vítreo, onde se destaca a textura eutaxítica e, muitas vezes, a textura parataxítica. Estes fato-
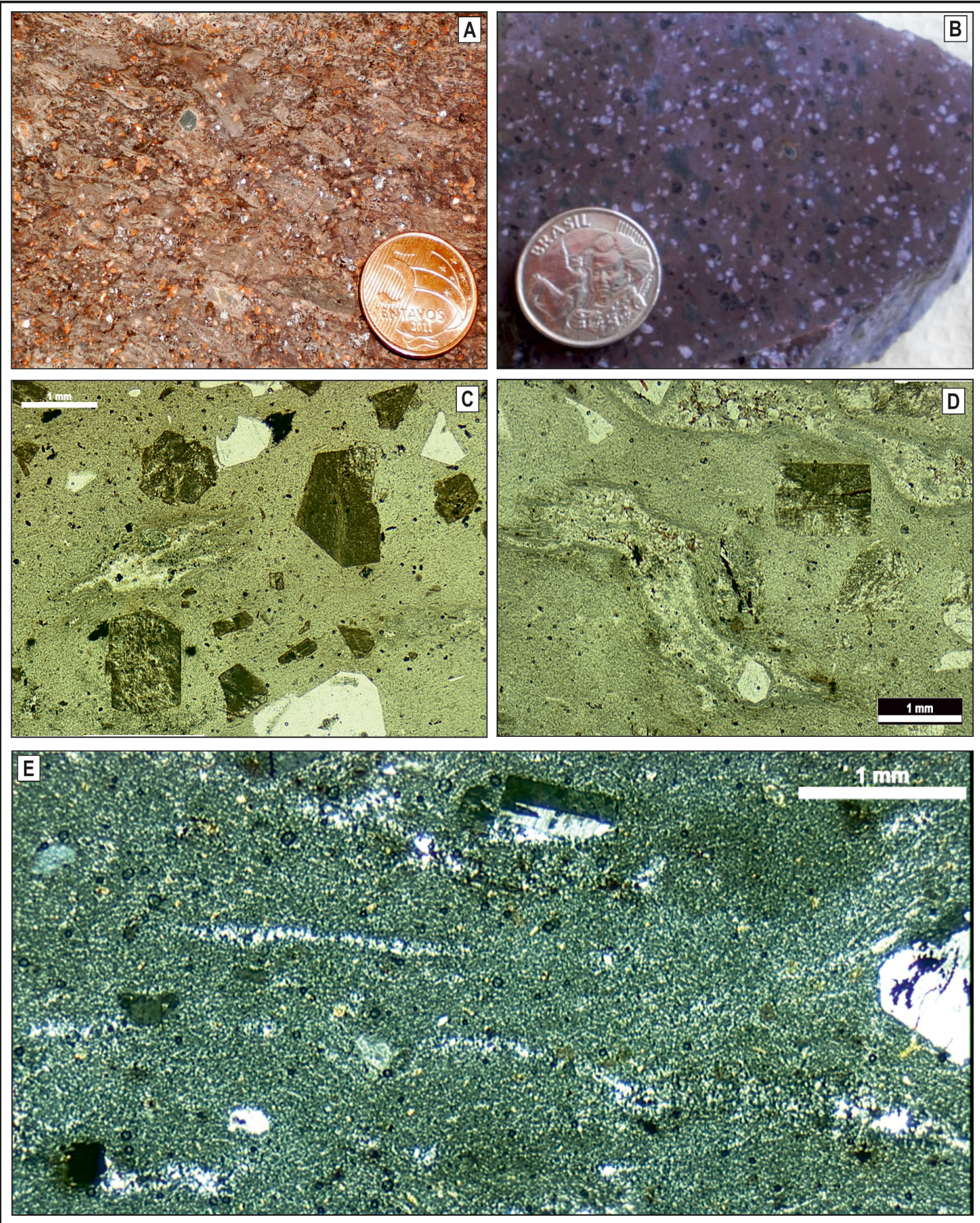

Figura 7. Aspectos petrográficos macro e microscópicos das rochas ignimbríticas da fácies reomórfica do Cerro dos Picados: A) ignimbrito soldado com textura eutaxítica nos fragmentos de púmices; B) ignimbrito fortemente soldado com grande quantidade de cristais quebrados; C) fragmentos de cristais de quartzo e feldspato alcalino quebrados e púmices estirados (LN); D) fragmentos de púmices estirados com textura eutaxítica e fenocristais de quartzo inclusos (LN); E) fotomicrografia panorâmica da lâmina mostrando os fragmentos de púmices estirados caracterizando a textura parataxítica (LP). 
res caracterizam estas rochas como ignimbritos do tipo lava-like (Fig. 7B). 0 termo "lava-like ignimbrites" (Ekren et al., 1984) é utilizado para ignimbritos com aspecto maciço e comportamento reológico semelhante a rochas efusivas, devido ao alto grau de soldagem dos depósitos.

Entre os piroclastos, predominam fenocristais e fragmentos de quartzo e feldspato alcalino e púmices estirados e deformados (Fig. 7C). Os fragmentos líticos são raros e, quando ocorrem, possuem composição riolítica. Os fragmentos de cristais são angulosos, com até $1 \mathrm{~mm}$ de comprimento (feldspato alcalino) ou reabsorvidos com diâmetro de 0,8 mm (quartzo). Feições de rotação dos cristais, relacionadas aos processos reomórficos, são observadas. Além de fragmentos, também ocorrem fenocristais de mesma mineralogia, subédricos a euédricos, com tamanhos entre 0,3 e 0,5 $\mathrm{mm}$, inclusos nos púmices (Fig. 7D) ou imersos na matriz.

Os fragmentos de púmices encontram-se achatados (fiamme), com morfologias variando desde lenticular até fitas estiradas. Estão devitrificados em agregados quartzo-feldspáticos com textura esferulítica e axiolítica. A textura eutaxítica é notável e constata-se em algumas porções dos de- pósitos a presença de reomorfismo, indicado principalmente pela textura parataxítica, caracterizada pelo forte estiramento de púmices (Fig. 7E).

A matriz é constituída por fiamme estirados e shards com geometria em espícula, de comprimento menor que $0,5 \mathrm{~mm}$. Os púmices mais estirados possuem uma relação comprimento [2 $\mathrm{mm}$ )/espessura $(0,1 \mathrm{~mm})]$ de $c a .20$ (Fig. 7E). Há porções devitrificadas para um intercrescimento granofírico microcristalino e outras com um material criptocristalino de baixo grau de cristalinidade e baixa birrefringência, ambas de composição quartzo-feldspática.

\subsection{Litoquímica}

As rochas da região do Tupanci (Tab. 1) possuem teores elevados de $\mathrm{SiO}_{2}$, variando de 73 a $77 \%$, característica utilizada para classificá-las como pertencentes aos "sistemas riolíticos de alta sílica", como descritos por Mahood \& Hildreth (1983) e Metz \& Mahood (1991). Os valores de álcalis $\left(\mathrm{Na}_{2} \mathrm{O}+\mathrm{K}_{2} \mathrm{O}>8,4 \%\right)$ também são elevados, enquanto os conteúdos de $\mathrm{Al}_{2} \mathrm{O}_{3}, \mathrm{CaO}$ e $\mathrm{MgO}$ são baixos, variando entre 11,34 a 12,$41 ; 0,02$ a 0,36 ; e $<0,01$ a 0,05 , respectivamente.

Tabela 1. Resultados de litoquímica para elementos maiores, menores, traços e terras raras nas amostras representativas dos Cerro Tupanci e do Cerro dos Picados. Elementos maiores em peso\% e traços e ETR em ppm.

\begin{tabular}{|c|c|c|c|c|c|c|c|c|c|c|c|c|c|c|}
\hline \multirow{2}{*}{ AMOSTRA } & \multicolumn{6}{|c|}{ CERRO TUPANCI } & \multicolumn{8}{|c|}{ CERRO DOS PICADOS } \\
\hline & CT 01 & CT 10 & CT 37 & CT 37A & CT 37B & CT $38 \mathrm{~A}$ & CT 43 & CT44 & CT 45 & CT 46 & CT 47 & CT 49 & CT 50 & CT 51 \\
\hline $\mathrm{SiO}_{2}$ & 76,40 & 75,58 & 76,93 & 76,26 & 73,28 & 76,30 & 75,41 & 77,09 & 76,69 & 76,38 & 77,44 & 76,65 & 76,83 & 76,35 \\
\hline $\mathrm{Al}_{2} \mathrm{O}_{3}$ & 11,66 & 12,23 & 11,27 & 12,41 & 12,01 & 12,20 & 11,94 & 11,97 & 11,90 & 11,81 & 11,66 & 11,34 & 11,54 & 11,53 \\
\hline $\mathrm{Fe}_{2} \mathrm{O}_{3 \mathrm{~T}}$ & 2,18 & 1,87 & 1,13 & 1,21 & 2,62 & 1,50 & 1,50 & 1,27 & 1,25 & 1,37 & 1,18 & 1,62 & 1,46 & 1,55 \\
\hline MnO & 0,01 & 0,04 & 0,00 & 0,00 & 0,11 & 0,03 & 0,01 & 0,01 & 0,02 & 0,03 & 0,01 & 0,01 & 0,04 & 0,02 \\
\hline MgO & 0,09 & 0,01 & 0,03 & 0,02 & 0,05 & $<0,01$ & 0,02 & $<0,01$ & 0,01 & 0,02 & 0,02 & 0,01 & 0,01 & 0,02 \\
\hline $\mathrm{CaO}$ & 0,02 & 0,02 & 0,03 & 0,04 & 0,12 & 0,36 & 0,03 & 0,31 & 0,32 & 0,35 & 0,34 & 0,16 & 0,26 & 0,22 \\
\hline $\mathrm{Na}_{2} \mathrm{O}$ & 3,61 & 3,80 & 1,96 & 3,46 & 3,62 & 4,12 & 4,03 & 4,23 & 4,13 & 4,12 & 3,93 & 3,74 & 3,87 & 4,00 \\
\hline $\mathrm{K}_{2} \mathrm{O}$ & 4,81 & 5,38 & 6,75 & 5,21 & 5,04 & 4,94 & 4,45 & 4,38 & 4,33 & 4,41 & 4,35 & 4,43 & 4,45 & 4,51 \\
\hline $\mathrm{TiO}_{2}$ & 0,21 & 0,22 & 0,19 & 0,22 & 0,20 & 0,07 & 0,06 & 0,06 & 0,06 & 0,06 & 0,05 & 0,08 & 0,07 & 0,07 \\
\hline $\mathrm{P}_{2} \mathrm{O}_{5}$ & 0,02 & 0,02 & 0,03 & 0,02 & $<0,01$ & 0,02 & 0,01 & 0,01 & 0,01 & 0,02 & $<0,01$ & $<0,01$ & $<0,01$ & $<0,01$ \\
\hline P.F. & 0,70 & 0,67 & 1,03 & 1,14 & 1,67 & 0,76 & 1,14 & 0,77 & 0,82 & 0,93 & 0,74 & 0,84 & 0,63 & 0,62 \\
\hline Total & 99,70 & 99,83 & 99,36 & 99,98 & 98,71 & 100,30 & 98,58 & 100,10 & 99,55 & 99,50 & 99,72 & 98,88 & 99,16 & 98,88 \\
\hline Ga & 26,0 & 26,0 & 23,0 & 23,0 & 23,0 & 31,0 & 28,0 & 29,0 & 28,0 & 28,0 & 28,0 & 26,0 & 27,0 & 28,0 \\
\hline $\mathrm{Rb}$ & 72,0 & 83,0 & 110,0 & 83,0 & 78,0 & 237,0 & 268,0 & 233,0 & 220,0 & 230,0 & 250,0 & 170,0 & 192,0 & 190,0 \\
\hline $\mathrm{Sr}$ & 16,0 & 8,0 & 33,0 & 14,0 & 8,0 & 5,0 & 4,0 & 5,0 & 5,0 & 6,0 & 5,0 & 3,0 & 3,0 & 3,0 \\
\hline Y & 68,0 & 72,0 & 72,0 & 73,0 & 62,0 & 154,0 & 107,0 & 163,0 & 138,0 & 134,0 & 131,0 & 135,0 & 136,0 & 119,0 \\
\hline $\mathrm{Zr}$ & 585,0 & 580,0 & 538,0 & 667,0 & 549,0 & 326,0 & 350,0 & 278,0 & 291,0 & 417,0 & 251,0 & 333,0 & 282,0 & 289,0 \\
\hline $\mathrm{Nb}$ & 23,0 & 24,0 & 23,1 & 26,0 & 22,0 & 37,7 & 63,0 & 57,0 & 62,0 & 60,0 & 47,0 & 34,0 & 33,0 & 35,0 \\
\hline $\mathrm{Ba}$ & 95,0 & 94,0 & 472,0 & 79,0 & 75,0 & 9,0 & 12,0 & 7,0 & 9,0 & 16,0 & 6,0 & 17,0 & 6,0 & 9,0 \\
\hline La & 167,0 & 136,0 & 35,9 & 79,5 & 172,0 & 39,8 & 102,0 & 46,0 & 42,3 & 44,1 & 35,1 & 44,5 & 47,7 & 34,1 \\
\hline $\mathrm{Ce}$ & 307,0 & 237,0 & 74,8 & 170,0 & 334,0 & 92,6 & 127,0 & 103,0 & 95,5 & 97,4 & 77,5 & 105,0 & 109,0 & 79,6 \\
\hline $\operatorname{Pr}$ & 34,1 & 29,3 & 8,8 & 20,1 & 35,7 & 11,9 & 24,9 & 12,4 & 11,0 & 11,1 & 9,0 & 13,6 & 13,3 & 9,8 \\
\hline $\mathrm{Nd}$ & 116,0 & 98,9 & 32,2 & 60,6 & 106,0 & 51,9 & 71,8 & 37,3 & 32,8 & 32,7 & 26,2 & 44,3 & 41,9 & 35,3 \\
\hline $\mathrm{Sm}$ & 19,9 & 17,4 & 6,4 & 12,9 & 18,7 & 12,6 & 22,0 & 13,6 & 11,3 & 10,7 & 9,3 & 15,6 & 14,6 & 12,5 \\
\hline Eu & 0,4 & 0,4 & 0,1 & 0,3 & 0,3 & 0,0 & 0,3 & $<0,05$ & 0,1 & 0,1 & $<0,05$ & 0,1 & $<0,05$ & $<0,05$ \\
\hline Gd & 16,7 & 15,7 & 8,5 & 11,7 & 14,6 & 17,9 & 19,8 & 17,1 & 12,9 & 12,4 & 11,4 & 18,4 & 17,1 & 14,7 \\
\hline $\mathrm{Tb}$ & 2,6 & 2,5 & 1,9 & 2,3 & 2,3 & 3,8 & 3,7 & 4,0 & 3,1 & 2,9 & 2,8 & 3,9 & 3,8 & 3,3 \\
\hline Dy & 12,5 & 12,5 & 12,1 & 13,2 & 12,1 & 24,0 & 19,7 & 25,5 & 19,8 & 19,8 & 18,6 & 24,1 & 23,5 & 20,6 \\
\hline Но & 2,3 & 2,3 & 2,4 & 2,7 & 2,4 & 4,7 & 3,7 & 5,6 & 4,5 & 4,5 & 4,3 & 5,2 & 5,0 & 4,5 \\
\hline $\mathrm{Er}$ & 7,2 & 7,1 & 7,3 & 7,5 & 6,6 & 14,4 & 10,1 & 15,5 & 12,5 & 13,4 & 12,8 & 14,1 & 13,5 & 12,4 \\
\hline $\mathrm{Tm}$ & 1,1 & 1,1 & 1,1 & 1,2 & 1,0 & 2,1 & 1,7 & 2,4 & 2,0 & 2,3 & 2,2 & 2,2 & 2,1 & 2,0 \\
\hline $\mathrm{Yb}$ & 6,5 & 6,5 & 6,9 & 7,6 & 6,5 & 12,4 & 10,9 & 14,5 & 12,4 & 15,1 & 13,7 & 12,4 & 12,1 & 12,0 \\
\hline $\mathrm{Lu}$ & 0,9 & 1,0 & 1,0 & 1,1 & 1,0 & 1,7 & 1,5 & 2,0 & 1,7 & 2,1 & 1,8 & 1,6 & 1,6 & 1,6 \\
\hline $\mathrm{Hf}$ & 14,5 & 14,2 & 13,9 & 16,6 & 13,8 & 13,5 & 15,2 & 13,2 & 12,7 & 16,4 & 13,0 & 13,3 & 12,3 & 12,5 \\
\hline $\mathrm{Ta}$ & 1,3 & 1,3 & 1,7 & 1,6 & 1,3 & 3,2 & 5,2 & 4,3 & 4,6 & 4,8 & 4,2 & 2,7 & 2,8 & 3,0 \\
\hline Th & 12,1 & 11,8 & 10,8 & 13,9 & 12,2 & 19,2 & 22,2 & 22,4 & 21,8 & 22,2 & 23,1 & 18,7 & 19,4 & 19,5 \\
\hline $\mathrm{U}$ & 1,8 & 1,8 & 2,5 & 2,5 & 2,7 & 6,1 & 4,3 & 7,3 & 7,2 & 7,3 & 8,0 & 4,2 & 5,6 & 4,6 \\
\hline
\end{tabular}


Segundo a razão álcalis total $\left(\mathrm{Na}_{2} \mathrm{O}+\mathrm{K}_{2} \mathrm{O}\right) v s$ $\mathrm{SiO}_{2}$ (TAS - Le Bas et al., 1986), as amostras são classificadas como riolitos (Fig. 8A), situando-se próximo ao limite entre os campos alcalinos e subalcalinos. $\mathrm{O}$ índice agpaítico, calculado pela razão molar $\mathrm{Na}_{2} \mathrm{O}+\mathrm{K}_{2} \mathrm{O}$ e $\mathrm{Al}_{2} \mathrm{O}_{3}$ é próximo à unidade $(>0,9)$, e no diagrama de Shand (Maniar \& Piccoli, $1989)$ constata-se que as razões entre alumina e álcalis também se concentram próxima à unidade (Fig. 8B). É importante salientar que este valor pode estar levemente modificado, pois a perda de álcalis durante a cristalização de magmas peralcalinos ou em processos de alteração pós-magmáticos (Leat et al., 1986) pode provocar variações nos índices de alumina-saturação.

No diagrama de classificação R1-R2 (De La Roche et al., 1980) as amostras ocupam o campo dos riolitos alcalinos (Fig. 8C), o que é também sugerido pelas razões $\mathrm{Zr} / \mathrm{TiO}_{2}$ vs. $\mathrm{SiO}_{2}$ e $\mathrm{Zr} / \mathrm{TiO}_{2}$ vs. $\mathrm{Nb} / Y$ (Winchester \& Floyd, 1977), com tendência comendítica/pantelerítica em algumas amostras do Cerro dos Picados (Fig. 8D).
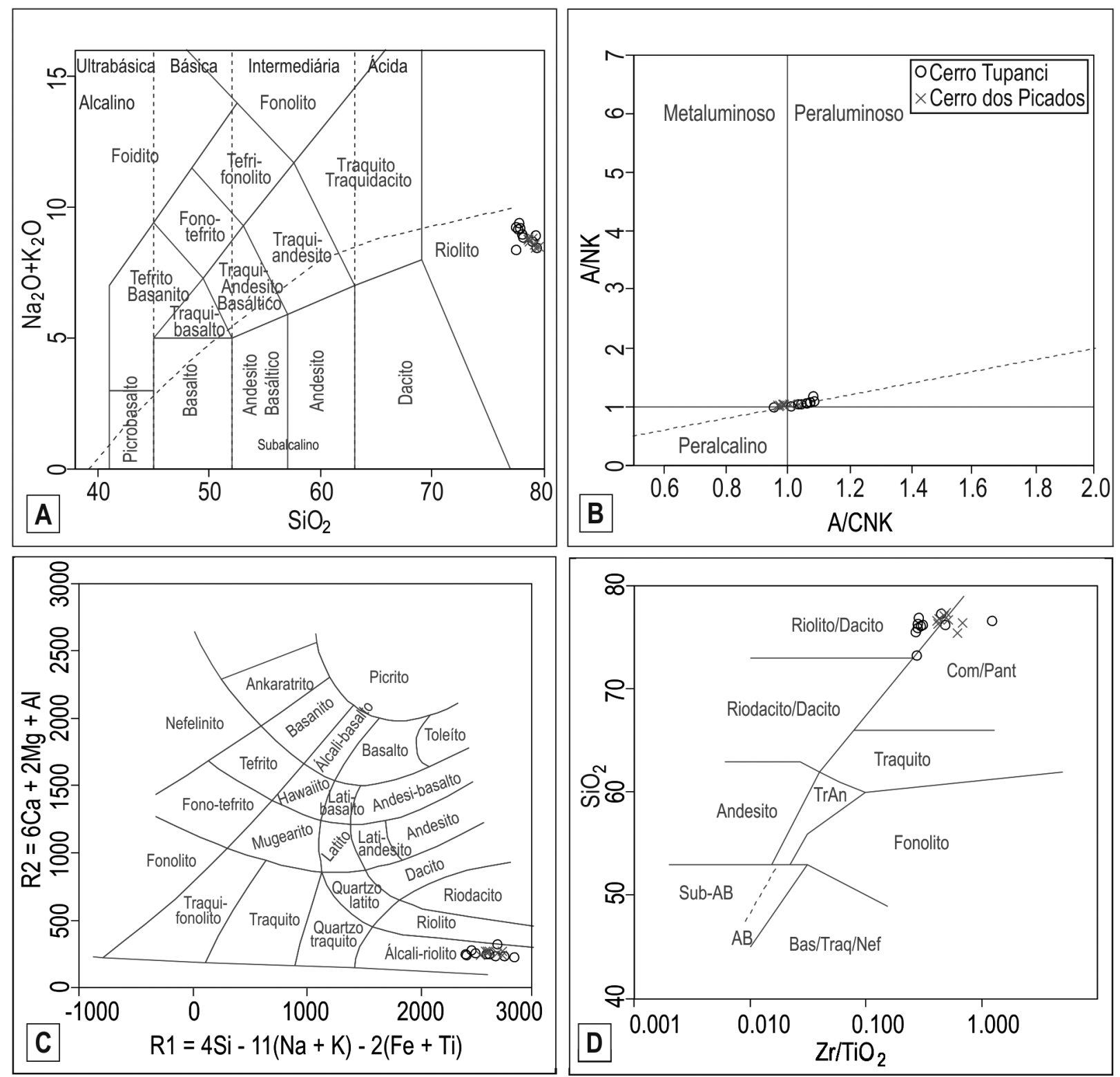

Figura 8. Amostras das rochas vulcânicas ácidas da região do Tupanci plotadas em diagramas de classificação litoquímica: A) diagrama TAS - razão álcalis vs. sílica (Le Bas et al., 1986); B) diagrama de Shand com as razões molares entre $\mathrm{Al}_{2} \mathrm{O}_{3} / \mathrm{Na}_{2} \mathrm{O}+\mathrm{K}_{2} \mathrm{O}$ vs. $\mathrm{Al}_{2} \mathrm{O}_{3} / \mathrm{Na}_{2} \mathrm{O}+\mathrm{K}_{2} \mathrm{O}+\mathrm{CaO}$ (Maniar \& Piccoli, 1989); C) diagrama de classificação R1 vs. R2 (De La Roche et al., 1980); D) diagrama de classificação $\mathrm{Zr} / \mathrm{TiO}_{2}$ vs.SiO 2 (Winchester \& Floyd, 1977). 
Nos diagramas binários de Harker (Fig. 9) observam-se duas tendências evolutivas, uma alto-Ti, representada por intrusivas do Cerro Tupanci e outra baixo-Ti, nas efusivas e piroclásticas do Cerro dos Picados.

Os teores de $\mathrm{TiO}_{2}$ foram utilizados como índice de diferenciação para minimizar o efeito da soma constante comum em sistemas alta-sílica. Em relação aos teores de $\mathrm{TiO}_{2}, \mathrm{~K}_{2} \mathrm{O}, \mathrm{Al}_{2} \mathrm{O}_{3}, \mathrm{MgO}$, $\mathrm{SiO}_{2}, \mathrm{FeO}^{\mathrm{t}}$ e o conteúdo total de $\mathrm{Na}_{2} \mathrm{O}+\mathrm{K}_{2} \mathrm{O}$, estes possuem uma correlação positiva, $\mathrm{o} \mathrm{P}_{2} \mathrm{O}_{5}$ é constante e o $\mathrm{Na}_{2} \mathrm{O}, \mathrm{CaO}$ e as razões $\mathrm{Na}_{2} \mathrm{O} / \mathrm{K}_{2} \mathrm{O}$ e CaO/ $\left(\mathrm{Na}_{2} \mathrm{O}+\mathrm{K}_{2} \mathrm{O}\right)$ apresentam uma correlação negativa. Estas variações podem ser explicadas devido a mecanismos de fracionamento prévio de minerais (e.g., plagioclásios).

Nos dois cerros observam-se altos valores para HFSE (Zr, Nb, Y), Ga e Rb, acompanhados de baixos valores para o Ba e Sr. Os teores de $\mathrm{Zr}$, Sr e Ba têm correlação positiva com o $\mathrm{TiO}_{2}$, enquanto
$\mathrm{Nb}, \mathrm{Y}, \mathrm{Rb}$ e Ga apresentam correlação negativa (Fig. 10).

Os valores de $\mathrm{Zr}$ são superiores a $500 \mathrm{ppm}$ para as amostras do CT, o que indicaria, segundo Leat et al. (1986), um caráter peralcalino para estas rochas. No CP os valores de $\mathrm{Zr}$ chegam a 420 ppm. Os valores de Rb, embora altos para os dois cerros, também se dividem em dois grupos, um com valores superiores a $170 \mathrm{ppm}$ no $\mathrm{CP}$ e outro com valores inferiores a $100 \mathrm{ppm}$ no CT. Os teores de $\mathrm{Nb}, \mathrm{Y}$ e Ga comportam-se da mesma maneira que o $\mathrm{Rb}$, com valores em geral $>50,130$ e $25 \mathrm{ppm}$ no $\mathrm{CP}$ e $<30,70$ e $26 \mathrm{ppm}$ no CT, respectivamente. Os teores de Ba e Sr comportam-se semelhantes aos do $\mathrm{Zr}$, com valores em geral $>70$ e 8 no CT e $<16$ e 6 no CP. Os altos teores para Zr, Nb, Y, Ga e $\mathrm{Rb}$, juntamente com os baixos teores de Ba e Sr são característicos de magmatismo ácido de afinidade alcalina (Pearce et al., 1984; Whalen et al., 1987; Nardi, 1991).

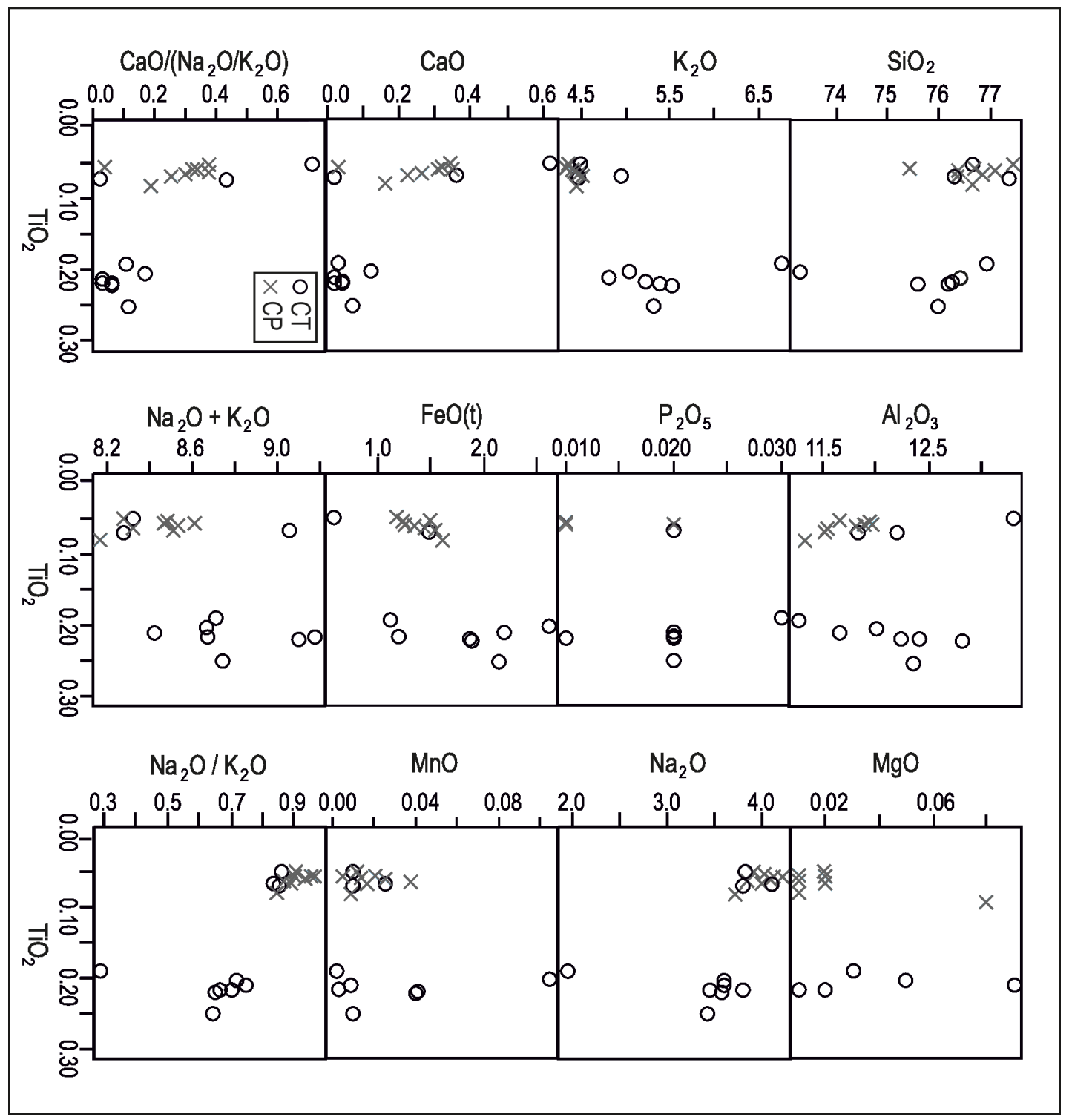

Figura 9. Diagramas binários mostrando a variação de elementos maiores (peso\%) em função da $\mathrm{TiO}_{2}$ (peso\%). 


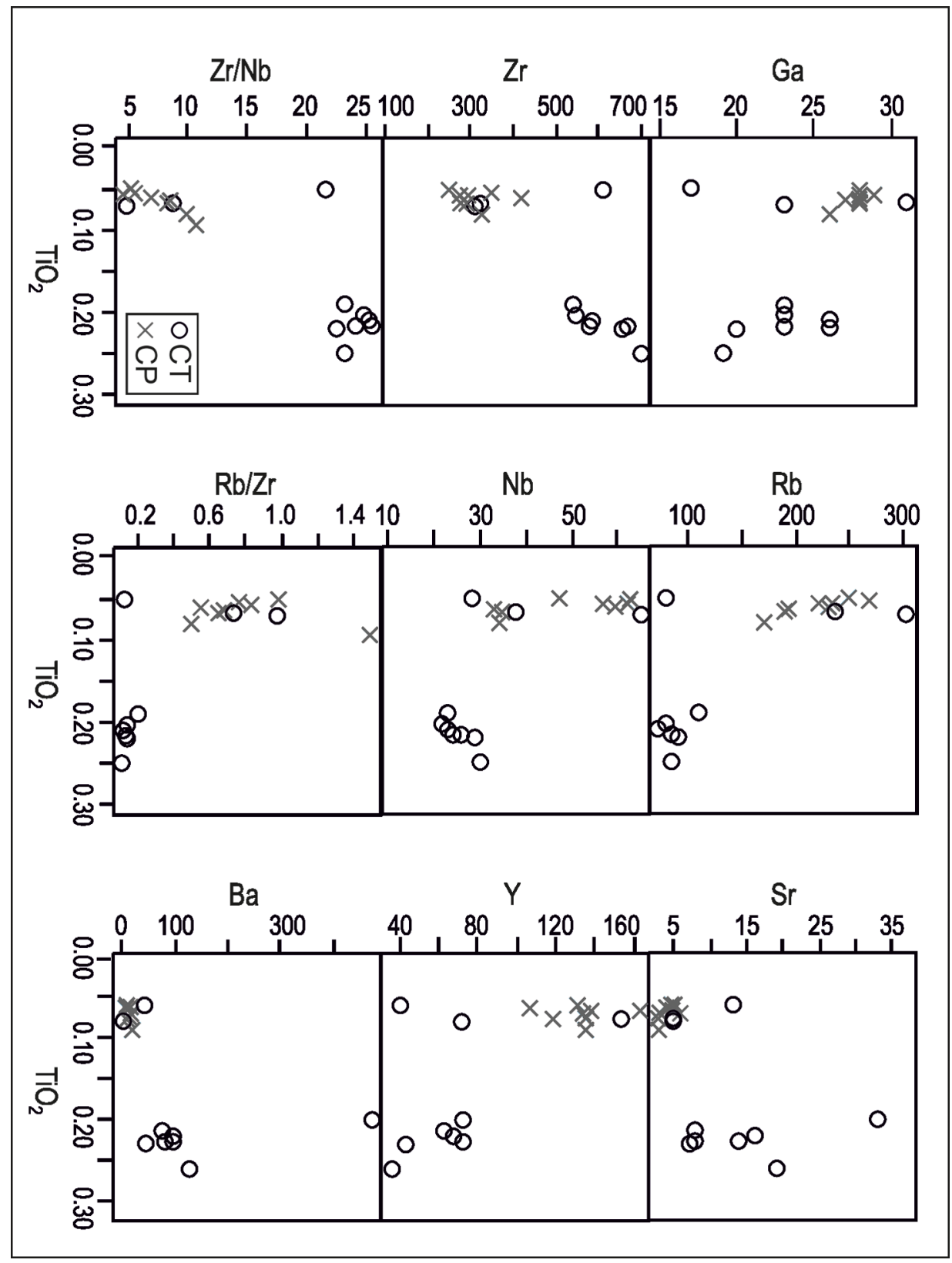

Figura 10. Diagramas binários mostrando a variação de elementos traços (ppm) em função da TiO 2 (peso\%).

Os elevados valores do índice agpaítico e de $\mathrm{Zr}$ indicam uma tendência peralcalina para estas rochas, constatando-se ainda uma natureza comendítica para o sistema (MacDonald, 1974; Le Maitre, 2002) (Fig. 11A). No diagrama Ta vs. Th (Fig. 11B), observa-se que as rochas vulcânicas ácidas da região do Tupanci aproximam-se de associações comendiíticas como Snowdon, Parys Mountain, Avoca, Huckleberry Ridge Tuff (Hildreth, 1981; Leat et al., 1986) e ao Platô do Taquarembó (Sommer et al., 1999; Wildner et al., 1999).

Quando normalizadas pelo ORG (Fig. 12A), as amostras de ambos os cerros apresentam um enriquecimento geral nos elementos mais incompatíveis, como evidenciado pela variação entre os valores normalizados do $\mathrm{Yb}$ para o $\mathrm{K}_{2} \mathrm{O}$. Observa-se também a anomalia negativa em Ba e o leve en- riquecimento em Ce, e também em $\mathrm{K}_{2} \mathrm{O}$ e $\mathrm{Rb}$ em relação ao $\mathrm{Nb}$. Estas características sugerem uma fonte mantélica, rica em elementos incompatíveis por um processo de contaminação crustal.

De acordo com Shellnut et al. (2009), a razão $\mathrm{Th} / \mathrm{Ta}$ pode ser indicativa da interação crosta-manto, com razões próximas a 2,0 para as rochas originadas por fusão mantélica, inferiores portanto aos valores esperados para aquelas originadas por fusão crustal (Th/Ta $\geq 6,9)$. Nas rochas do CT (alto-Ti), predominam razões $\mathrm{Th} / \mathrm{Ta}$ maiores do que 6,9 , enquanto as rochas do CP (baixo-Ti) apresentam valores entre 6,9 e 4,2, indicando uma menor contribuição crustal na sua origem.

Segundo Eby $(1990,1992)$, o fracionamento de magmas do tipo "A" tem pouco efeito na razão $\mathrm{Y} / \mathrm{Nb}$, a qual poderia também ser utilizada para 
indicar a fonte principal do magmatismo. Magmas derivados de fontes mantélicas possuem razões $\mathrm{Y} /$ $\mathrm{Nb}$ menores que 1,2, enquanto aqueles de origem crustal esta razão é superior a 1,2. Estes critérios geoquímicos sugerem um forte componente crustal na origem das rochas vulcânicas dos Cerros Tupanci e dos Picados.
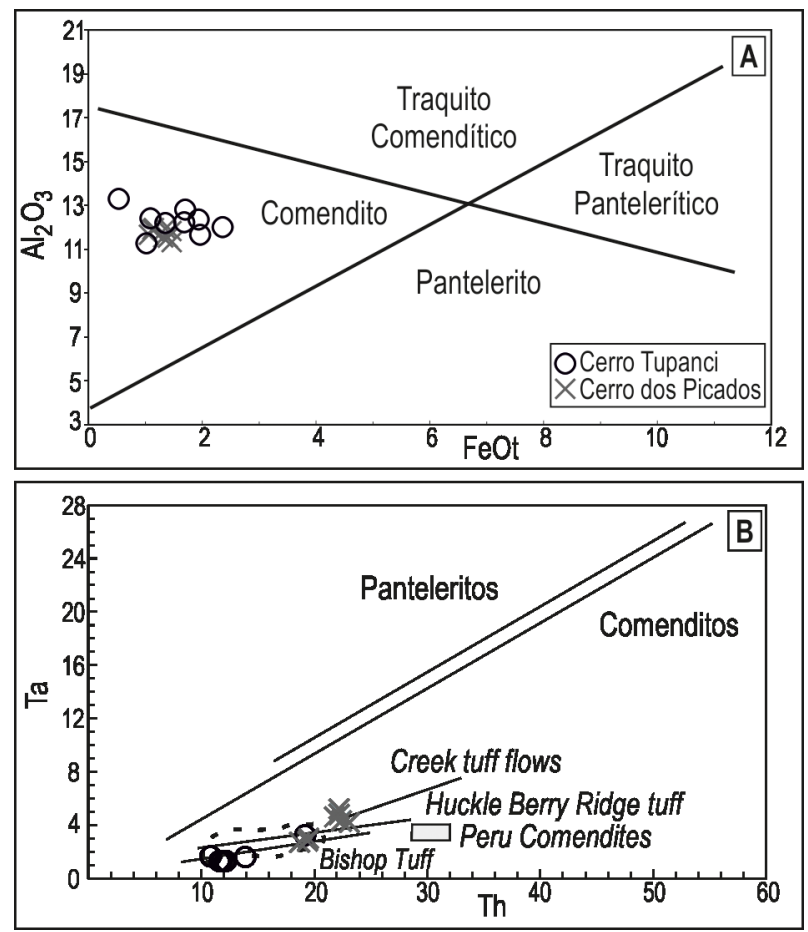

Figura 11. Diagramas de discriminação de riolitos comendíiticos/panteleríticos: A) diagrama $\mathrm{Al}_{2} \mathrm{O}_{3}$ vs. FeOt (MacDonald, 1974); B) Diagrama Ta vs. Th (Leat et al., 1986).

Em ambos os cerros as rochas apresentam concentração moderada a elevada de ETR ( $\Sigma$ ETR= 198 - 694 ppm). 0 fracionamento entre ETRL e ETRP é baixo nas amostras do $\mathrm{CP}\left(\mathrm{La}_{\mathrm{N}} / \mathrm{Yb}_{\mathrm{N}}=1,7-\right.$ $6,9)$ e um pouco mais elevado nas amostras do CT $\left(\mathrm{La}_{\mathrm{N}} / \mathrm{Yb}_{\mathrm{N}}=3,48-17,64\right)$. De um modo geral, o fracionamento dos ETRL é maior que o dos ETRP, com razões $\mathrm{La}_{N} / \mathrm{Sm}_{\mathrm{N}}$ mais altas $(1,6-5,1)$ que as razões $\mathrm{Tb}_{\mathrm{N}} / \mathrm{Lu}_{\mathrm{N}}(1,2-1,5)$. Ocorre em todas as amostras uma forte anomalia negativa em $\mathrm{Eu}\left(\mathrm{Eu} / \mathrm{Eu}^{*}=0,01\right.$ - 0,19), que está provavelmente relacionada ao seu caráter bivalente e consequente fracionamento de feldspatos (Fig. 12B). Assim como distinguido para a Formação Acampamento Velho no Platô da Ramada por Sommer et al. (2005b), observa-se nos riolitos alto Ti da região (CT) um enriquecimento em ETR, principalmente em ETRL, enquanto que as rochas ácidas baixo $\mathrm{Ti}(\mathrm{CP})$ mostram um padrão mais horizontalizado (Fig. 14AB).Estas características geoquímicas são também descritas em outras ocorrências da Formação Acampamento Velho por Sommer et al. (2005b, 2006), sendo que nestas foram identificados grupos de basaltos-riolitos alto-Ti e baixo-Ti. A condição comagmática destes dois polos e a relação petrogenética entre eles não é ainda compreendida. As diferenças composicionais observadas entre os grupos alto e baixo-Ti são atribuídas a diferentes taxas de fusão de um manto dominantemente litosférico, previamente afetado por subducção.
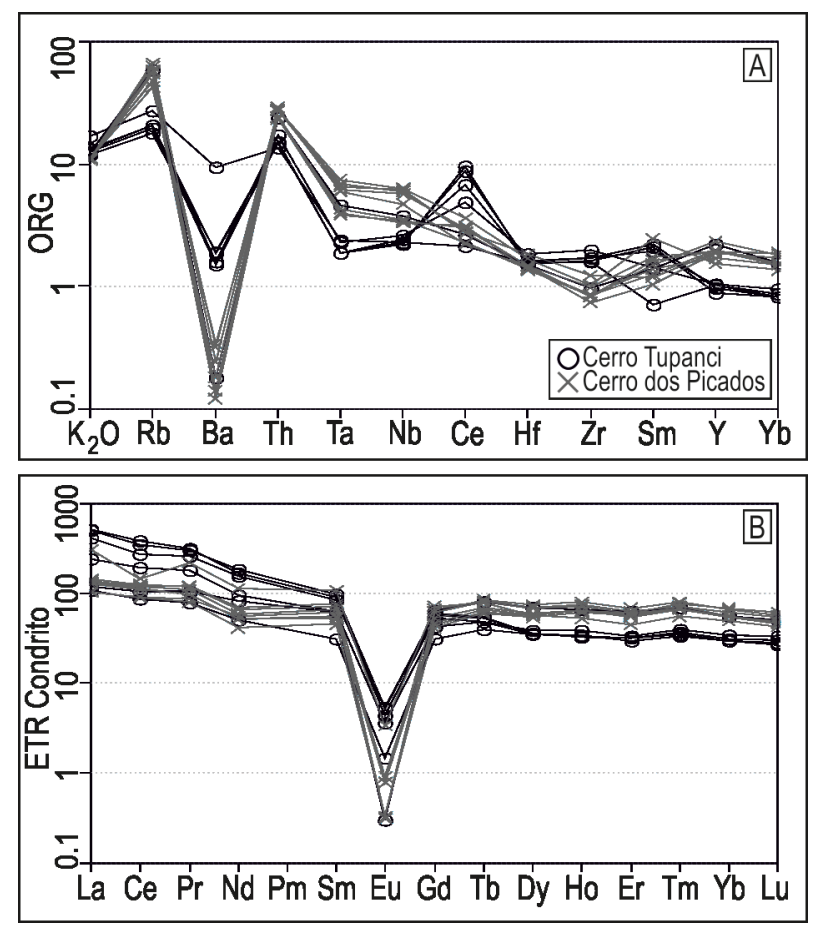

Figura 12. Diagramas multi-elementares: A) traços e ETR normalizados pelo ORG (Pearce et al., 1984); B) ETR normalizados pelo condrito (Nakamura, 1974).

Nos diagramas de ambientes tectônicos de Pearce et al. (1984), as amostras do CT localizam-se mais próximas do campo pós-colisional (Fig. 13A), enquanto as rochas do CP concentram-se mais no campo dos granitóides intra-placa, o que é coerente com o aumento da peralcalinidade. Nos diagramas de classificação de granitóides propostos por Whalen et al. (1987), todas as amostras ocupam o campo dos granitos do tipo "A" (Fig. 13B), os quais são alcalinos e anorogênicos. Esta classificação é confirmada pelos valores de $\left(10^{4 *} \mathrm{Ga}\right) / \mathrm{Al}>2,6$, $\mathrm{Ce}+\mathrm{Y}+\mathrm{Nb}+\mathrm{Zr}>500 \mathrm{ppm}$ e $\mathrm{FeOt} / \mathrm{FeOt}+\mathrm{MgO}>0,9$, como proposto por Nardi \& Bitencourt (2009) para o magmatismo granítico pós-colisional do tipo "A" no sul do Brasil.

Os padrões geoquímicos dos cerros estudados são similares aos descritos para as rochas vulcânicas ácidas da Formação Acampamento Velho em outras ocorrências (Sommer et al., 2005b). Contudo, as rochas alto-Ti (CT) possuem valores 
mais baixos para $\mathrm{Rb}, \mathrm{Nb}$ e $\mathrm{Y}$, e mais altos para $\mathrm{Zr}$ e Ce, quando comparadas com as rochas baixo-Ti (CP), o que sugere localizadamente uma diferente evolução para esta associação de rochas vulcânicas ácidas (Fig. 14).

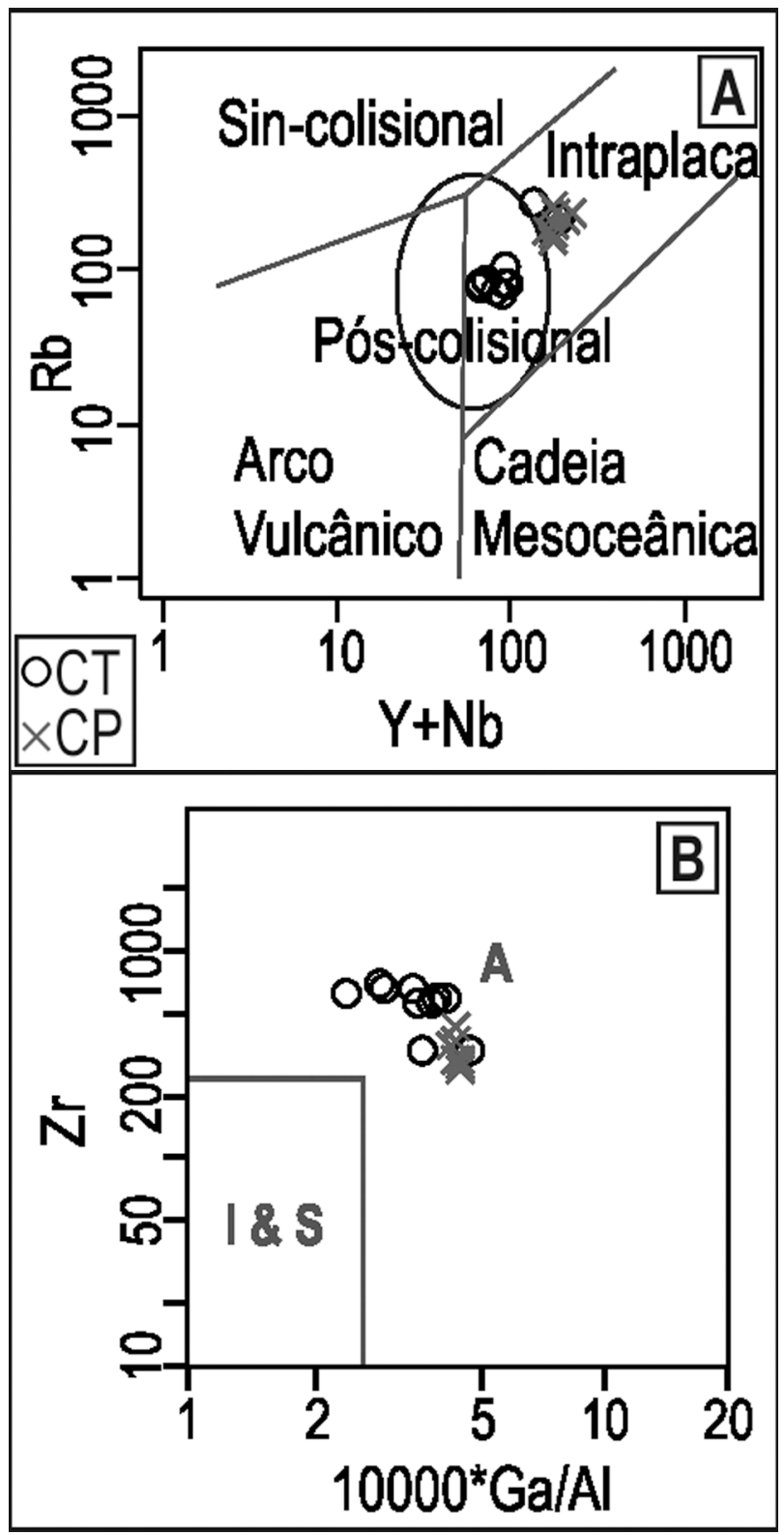

Figura 13. Diagramas discriminantes de ambientes tectônicos e classificação de rochas graníticas: $\mathrm{A}) \mathrm{Rb} v s$. $\mathrm{Y}+\mathrm{Nb}$ (Pearce et al., 1984); B) Zr vs. $10000^{*} \mathrm{Ga} / \mathrm{Al}$ (Whalen et al., 1987).

De maneira geral, os dados de elementos maiores, traços e ETR permitem classificar o magmatismo da região do Tupanci como supersaturado em sílica, semelhante aos sistemas alta sílica, de afinidade alcalina sódica e tendência levemente peralcalina, análogo aos granitos do tipo "A" do magmatismo neoproterozoico pós-colisional no ESRG.
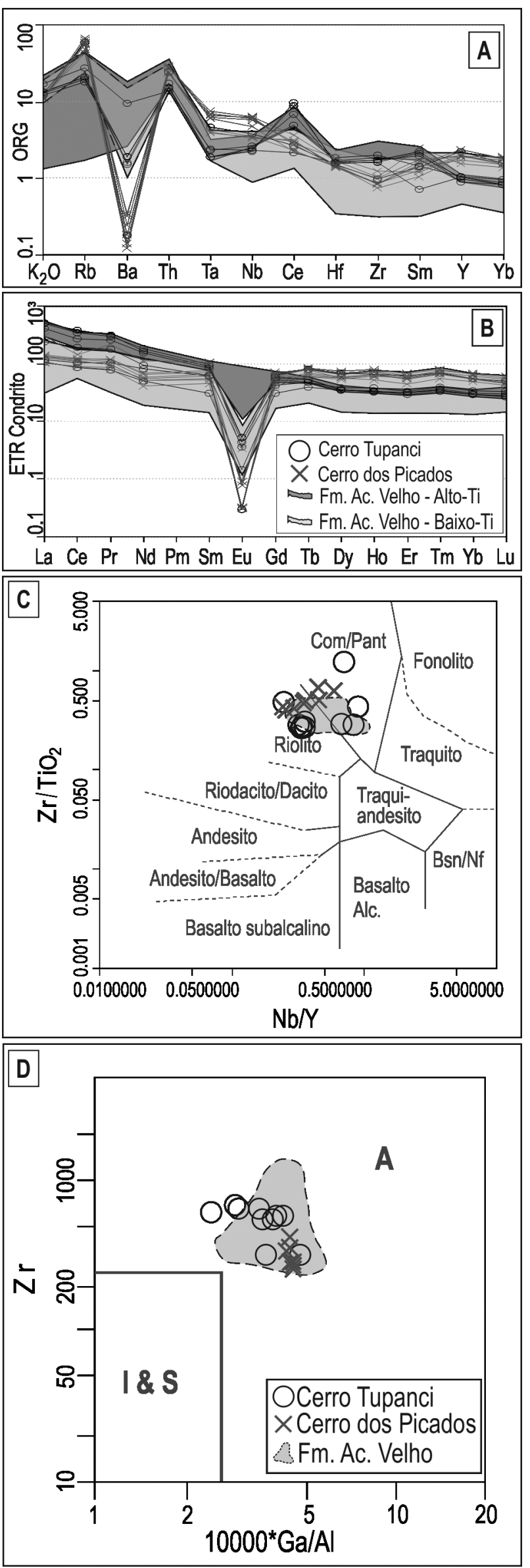

Figura 14. Comparação dos dados das amostras da região do Tupanci com outras ocorrências de rochas vulcânicas ácidas da Fm. Acampamento Velho: A) traços e ETR normalizados pelo ORG (Pearce et al., 1984); B) ETR normalizados pelo con- 
drito (Nakamura, 1974); C) diagrama de classificação Nb/Y vs. $\mathrm{Zr} / \mathrm{TiO}_{2}$ (Winchester \& Floyd, 1977); D) diagrama discriminante de ambiente tectônico $\mathrm{Zr} v s .1000^{*} \mathrm{Ga} / \mathrm{Al}$ (Pearce et al., 1984).

\section{Conclusões}

A variação faciológica das rochas vulcânicas ácidas na região do Tupanci permitiu diferenciar dois processos eruptivos, relacionados a depósitos efusivos e explosivos contemporâneos, além de intrusões de riolitos hipoabissais. Estas unidades ocorrem associadas às formações Hilário e Maricá como "janelas do embasamento", controladas por falhamentos com sentido NE-SW e recobertas por rochas sedimentares da Bacia do Paraná e sedimentos aluvionares quaternários.

o Cerro Tupanci pode ser interpretado como uma intrusão subvulcânica, constituída por riolitos porfiríticos, mostrando, em algumas porções, forte foliação de fluxo, microbrechas e textura esferulítica de devitrificação em alta temperatura. No Cerro dos Picados ocorrem depósitos efusivos, com riolitos texturalmente semelhantes, porém com matriz de aspecto vítreo e rochas piroclásticas, caracterizadas por ignimbritos riolíticos. Os ignimbritos podem ser divididos em duas fácies, uma com ignimbritos ricos em líticos, com alguns púmices devitrificados e pouco estirados, além de pequenos e raros cristaloclastos, e outra com ignimbritos reomórficos, com abundância em púmices devitrificados e proeminente textura eutaxítica, maior freqüência de cristaloclastos e raros litoclastos. A correlação estratigráfica dos diferentes eventos é dificultada devido a pequena exposição nos afloramentos em ambos os cerros.

Sistemas vulcânicos riolíticos, como o observado na região do Tupanci, abrangendo depósitos efusivos e ignimbríticos com alto grau de soldagem, ricos em fragmentos juvenis, normalmente são característicos de ambientes do tipo caldeira, com intrusões associadas, ou formados por desabamento de domos ou coulées. Em ambos os casos é comum que os ignimbritos tenham a sua origem vinculada a fluxos piroclásticos de alta temperatura e gerados a baixas colunas de erupção.

Os dados litoquímicos obtidos permitem classificar o magmatismo como supersaturado em sílica, semelhante aos sistemas de alta sílica, de afinidade alcalina e tendência metaluminosa a levemente peralcalina, com características de magmas relacionados a ambientes anorogênicos. Foram identificados dois trends geoquímicos em função do teor de $\mathrm{TiO}_{2}$, que correspondem ao contexto geológico de cada ocorrência: Alto-Ti, representado pelas rochas intrusivas do Cerro Tu- panci, e Baixo-Ti, nas rochas extrusivas (efusivas e piroclásticas) do Cerro dos Picados. As diferenças composicionais observadas são atribuídas aos estágios finais do magmatismo pós-colisional no Sul do Brasil e podem refletir diferentes taxas de fusão de um manto dominantemente litosférico, previamente afetado por subducção e metassomatismo (Wildner et al., 2002; Sommer et al., 2005a). As rochas vulcânicas ácidas do Tupanci representariam a etapa final de uma sequência magmática tipicamente pós-colisional, que evoluiu desde termos sub-alcalinos alto-K à shoshoníticos e, por fim, alcalino sódicos, observados na porção extremo sul do Brasil, no final do ciclo orogênico Brasiliano - Pan-Africano (Nardi \& Bonin, 1991; Gastal \& Lafon, 1998, 2001; Bitencourt \& Nardi, 2000; Wildner et al., 2002; Sommer et al., 2005a; Nardi \& Bitencourt, 2009). Sistemas deste tipo são também identificados em outros locais do mundo, como nas Associações Snowdonia e Parys Mountain, no Reino Unido (Leat et al., 1986), Devine Canyon Tuff, nos Estados Unidos (Greene, 1973) e no vulcanismo miocênico pós-colisional do Eastern Rif, em Marrocos (El Bakkali et al., 1998), sendo caracterizados pelo desenvolvimento de zonas de cisalhamento com magmatismo granítico associado e bacias do tipo strike-slip onde os eventos vulcânicos e sedimentares são preservados, assim como proposto por Bonin (2004) para a evolução do cinturão Alpino a partir do final da Orogênia Variscana na Europa.

Os dados petrográficos e litoquímicos das rochas vulcânicas ácidas da região do Tupanci indicam uma vinculação genética com o magmatismo da Formação Acampamento Velho, sendo similares aos riolitos alcalinos da região do Platô da Ramada (Sommer et al., 2005b) e do Platô do Taquarembó (Sommer et al., 1999), relacionados com o magmatismo neoproterozoico pós-colisional do tipo "A" no Escudo Sul-Rio-Grandense.

Agradecimentos - Ao CNPq e FAPERGS pelo apoio financeiro (CNPq Proc. 303584/2009-2, 473683/2007, 5470641/2008-8, 470203/2007-2, 302213/2012-0, 471402/2012-5, 303038/2009-8 e 4705052010-9; FAPERGS Proc. 100798,12/1180-8; PRONEX: 10/00456). Aos revisores do trabalho e aos editores da revista Pesquisas em Geociências por seus comentários e sugestões que auxiliaram a aprimorar o presente manuscrito.

\section{Referências}

Almeida, D.P.M., Zerfass, H., Basei, M.A., Petry, K. \& Gomes, C.H. 2002. The Acampamento Velho Formation, a Lower Cambrian Bimodal Volcanic Package: Geo- 
chemical and Stratigraphic Studies from the Cerro do Bugio, Perau and Serra de Santa Bárbara (Caçapava do Sul, RS - Brazil). Gondwana Research, 5 (3): 721-733.

Almeida, D.P.M., Conceição, R.V., Chemale Jr., F., Koester, E., Borba, A.W. \& Petry, K. 2005. Evolution of heterogeneous mantle in the Acampamento Velho and Rodeio Velho volcanic events, Camaquã Basin, southern Brazil. Gondwana Research, 8(4): 479-492.

Almeida, F.F.M., Hasui, Y., Brito Neves, B.B. \& Fuck, R.A. 1981. Brazilian structural provinces: an introduction. Earth Sciences Review, 17: 1-29.

Almeida, R.P., Janikian, L., Fragoso-César, A.R. \& Fambrini, G. L. 2010. The Ediacaran to Cambrian rift system of Southeastern South America: tectonic implications. The Journal of Geology, 118: 145-161.

Babinski, M., Chemale Jr., F., Hartmann, L.A., Van Schmus, W.R. \& Silva, L.C. 1996. Juvenile accretion at 750-700 Ma in southern Brazil. Geology, 24: 439-442.

Babinski, M., Chemale Jr., F., Van Schmus, W. R., Hartmann, L. A. \& Silva, L. C. 1997. U-Pb and Sm-Nd geochronology of the Neoproterozoic Granitic-Gneissic Dom Feliciano Belt, Southern Brazil. Journal of South American Earth Sciences, 10(3-4): 263-274

Bitencourt, M.F.A.S. \& Nardi, L.V.S. 2000. Tectonic setting and sources of magmatism related to the Southern Brazilian Shear Belt. Revista Brasileira de Geociências, 30: 184-187.

Bonin, B. 2004. Do coeval mafic and felsic magmas in post-collisional to within-plate regimes necessarily imply two contrasting, mantle and crustal, sources? A review. Lithos, 78: 1-24.

Borba, A.W. 2006. Evolução geológica da "Bacia do Camaquã" (Neoproterozoico e Paleozoico inferior do Escudo Sul-Rio-Grandense, RS, Brasil): uma visão com base na integração de ferramentas de estratigrafia, petrografia e geologia isotópica. Porto Alegre, 121p. Tese de Doutorado, Programa de Pós-Graduação em Geociências. Instituto de Geociências. Universidade Federal do Rio Grande do Sul.

Borba, A.W., Maraschin, A.J., Noronha, F.L., Casagrande, J. \& Mizusaki, A.M.P. 2007. Provenance of the sedimentary rocks of the Bom Jardim Group (Neoproterozoic, southern Brazil): evidence from petrography, geochemistry and Neodymium isotopes. Latin American Journal of Sedimentology and Basin Analysis, 14: 25-42.

Brito Neves, B.B. \& Cordani, U.G. 1991.Tectonic evolution of South America during Late Proterozoic. Precambrian Research, 53: 23-40.

Brito Neves, B.B., Campos Neto, M.C. \& Fuck, R.A. 1999. From Rodinia to eastern Gondwana: an approach to the Brasiliano-Pan African cycle and orogenic collage. Episodes, 22: 155-166.

Buckowski, N., Sommer, C.A., Lima, E.F., Leitzke, F.P., Oliveira, D.S. \& Sartori, L.S. 2010. Estudo comparativo entre os lamprófiros espessartíticos da região de Vila Nova do Sul e Lavras do Sul, RS. In: CONGRESSO BRASILEIRO DE GEOLOGIA, 45, 2010, Belém. Anais... Belém, SBG Núcleo Norte, v. 1, p. 110.

Chemale Jr., F. 2000. Evolução Geológica do Escudo Sul- -rio-grandense. In: De Ros, L.F. \& Holz, M. (eds.). Geologia do Rio Grande do Sul. Porto Alegre, CIGO/ UFRGS, p. 13-52.

De La Roche, H., Leterrier, J. \& Grandclaude, P. 1980. A classifícation of volcanic and plutonic rocks and associations. Chemical Geology, 29: 183-210.

Eby, G.N. 1990. The A-type granitoids: a review of their occurrence and chemical characteristics and speculations on their petrogenesis. Lithos, 26: 115-134.

Eby, G.N. 1992. Chemical subdivision of the A-type granitoids: petrogenetic and tectonic implications. Geology, 20: 641-644.

Ekren, E.B., McIntyre, D.H. \& Bennet, E.H. 1984. High temperature, large volume lava like flow tuffs without calderas in Southern Idaho. U.S. Geological Survey Prof. Papers, 1272: 1-73.

El Bakkali, S., Gourgaud, A., Bourdier, J.L., Bellon, H. \& Gundogdu, N. 1998. Post-collision neogene volcanism of the Eastern Rif (Morocco): magmatic evolution through time. Lithos, 45: 523-543.

Fernandes, L.A.D., Menegat, R., Costa, A.F.U., Koester, E., Porcher, C.C., Tommasi, A., Kraemer, G., Ramgrab, G.E. \& Camozzato, E. 1995. Evolução tectônica do Cinturão Dom Feliciano no Escudo Sul-rio-grandense: PARTE I - uma contribuição a partir do registro geológico. Revista Brasileira de Geociências, 25(4): 351-374.

Fragoso-César, A.R.S., Fambrini, G.L., Almeida, R.P., Pelosi, A.P.M.R., Janikian, L., Riccomini, C., Machado, R., Nogueira, A.C.R. \& Saes, G.S. 2000. The Camaquã extensional basin: Neoproterozoic to Early Cambrian sequences in southernmost Brazil. Revista Brasileira de Geociências, 30: 438-441.

Fragoso-César, A.R.S., Almeida, R.P., Fambrini, G.L., Pelosi, A.P.M.R. \& Janikian. L. 2003. A Bacia do Camaquã: um sistema intracontinental anorogênico de rifts do Neoproterozoico III, Eopaleozoico no Rio Grande do Sul. In: ENCONTRO SOBRE A ESTRATIGRAFIA DO RIO GRANDE DO SUL, 1, Porto Alegre. Boletim de Resumos. Porto Alegre, SBG, v. 1, p. 139-144.

Gastal, M.C.P. \& Lafon, J.M. 1998. Gênese e evolução dos granitóides metaluminosos de afinidade alcalina da porção oeste do escudo sul-rio-grandense: geoquímica e isótopos de $\mathrm{Rb}-\mathrm{Sr}$ e $\mathrm{Pb}-\mathrm{Pb}$. Revista Brasileira de Geociências, 28: 11-28.

Gastal, M.C.P. \& Lafon, J.M. 2001.Novas idades 207Pb/ $206 \mathrm{~Pb}$ e geoquímica isotópica Nd-Sr para granitóides shoshoníticos e alcalinos das regiões de Lavras do Sul e Taquarembó, RS. In: CONGRESSO BRASILEIRO DE GEOQUÍMICA, 8, 2001, Curitiba. Anais..., Curitiba, SBGE0, v.1, p.21-26.

Greene, R.C. 1973. Petrology of the welded tuff of Devine Canyon, southeastern Oregon. U.S. Geological Survey Professional Paper, 792: 1-26.

Gresse, P.G., ChemaleJr., F., Silva, L.C., Walraven, F. \& Hartman, L.A. 1996. Late to post-orogenic basins of the Pan-African-Brasiliano collision orogen in southern Africa and southern Brazil. Basin Research, 8: 157-171.

Hartmann, L.A., Leite, J.A.D., Silva, L.C., Remus, M.V.D., Mcnaughton, N.J., Groves, D.I., Fletcher, I.R., San- 
tos, J.O.S. \& Vasconcellos, M.A.Z. 2000. Advances in SHRIMP geochronology and their impact on understanding the tectonic andmetallogenic evolution of southern Brazil. Australian Journal of Earth Sciences, 47: 829-844.

Hartmann, L.A., Chemale Jr., F. \& Philipp, R.P. 2007. Evolução Geotectônica do Rio Grande do Sul no Pré-Cambriano. In: Iannuzzi, R. \& Frantz, J.C. (eds.). 50 Anos de Geologia. Instituto de Geociências. Contribuições. Porto Alegre, Comunicação e Identidade, p. 97123.

Hartmann, L.A., Philipp, R.P., Santos, J.O.S. \& Mcnaughton, N.J. 2011.Time frame of 753-680Ma juvenile accretion during the São Gabriel orogeny, southern Brazilian Shield. Gondwana Research, 19: 84-99.

Hildreth, W. 1981. Gradients in silicic magma chambers: implications for lithospheric magmatism. Journal of Geophysical Research, 86: 10153-10192.

Janikian, L., Almeida R.P., Trindade, R.I.F., Fragoso-César, A.R.S., D’Agrella-Filho, M.S., Dantas, E.L. \& Tohver, E. 2008. The continental record of Ediacaran volcano-sedimentary successions in southern Brazil and its global implications. Terra Nova, 20: 259-266.

Janikian, L., Almeida, R.P., Fragoso-Cesar, A.R.S., Martins, V.T.S., Dantas, E.L., Tohver, E., McReath, I. \& D’Agrella-Filho, M.S. 2012. Ages (U Pb SHRIMP and LA ICPMS) and stratigraphic evolution of the Neoproterozoic volcano-sedimentary successions from the extensional Camaquã Basin, Southern Brazil. Gondwana Research, 21: 466-482.

Jost, H. \& Hartmann, L.A. 1984. Província Mantiqueira - Sector Meridional. In: Almeida, F.F.M. \& Hasui, Y. (eds.). $O$ Pré-Cambriano do Brasil. São Paulo, Edgard Blücher, p. 345-368.

Leat, P.T., Jackson, S.E., Thorpe, R.S. \& Stillman, C.J. 1986. Geochemistry of bimodal basalt-subalkaline/peralkaline rhyolite provinces within the Southern British Caledonides. Journal of the Geological Society of London, 143: 259-273.

Le Bas, M.J., Le Maitre, R.W., Streckeisen, A. \& Zanettin, B. 1986. A chemical classification of volcanic rocks on the total alkali-silica diagram. Journal of Petrology, 27(3): 745-750.

Le Maitre, R.W. 2002. Igneous rocks: a classification and glossary of terms (2 ed.). Cambridge, Cambridge University Press, 252p.

Leite, J.A.D., Hartmann, L.A., McNaughton, N.J. \& Chemale Jr., F. 1998. SHRIMP U/Pb zircon geochronology of Neoproterozoic juvenile and crustal-reworked terranes in southernmost Brazil. International Geology Review, 40: 688-705.

Liégeois, J.P. 1998. Some words on the post-collisional magmatism. Preface to Special Edition on Post-Collisional Magmatism. Lithos, 45: 15-17.

Lima, E.F., Sommer, C.A. \& Nardi, L.V.S. 2007. O vulcanismo neoproterozoico-ordoviciano no Escudo Sul-Rio-Grandense: os ciclos vulcânicos da Bacia do Camaquã. In: Iannuzzi, R. \& Frantz, J.C. (eds.). 50 Anos de Geologia. Instituto de Geociências. Contribuições. Porto Alegre, Comunicação e Identidade, p. 79-95.
Logfren, G. 1971. Experimentally produced devitrification textures in natural rhyolitic glasses. Geological Society of America Bulletin, 82: 111-124.

MacDonald, R. 1974. Nomenclature and Petrochemistry of the Peralkaline Oversaturated Extrusive Rocks. Bulletin Volcanologique, 38: 498-516.

Mahood, G.A. \& Hildreth, W. 1983. Nested calderas and trapdoor uplift at Pantelleria, Strait of Sicily. Geology, 2: 722-726.

Maniar, P.D. \& Piccoli, P.M. 1989.Tectonic discrimination of granitoids. Geological Society of America Bulletin, 101: 635-64.

Manley, C.R. 1995. How voluminous rhyolite lavas mimic rheomorphic ignimbrites: Eruptive style, emplacement conditions, and formation of tuff-like textures. Geology, 23(4): 349-352.

Menegotto, E. \& Medeiros, E.R. 1976. Contribuição ao estudo das rochas ígneas ácidas da região da Serra Tupanci, RS. In: CONGRESSO BRASILEIRO DE GEOLOGIA, 29, Ouro Preto. Anais..., Ouro Preto, SBGEO, v. 2, p. 427-432.

Metz, J.M. \& Mahood, G.A. 1991.Development of the Long Valley, California, magma chamber record in precaldera rhyolite lavas of glass Mountain. Contributions to Mineralogy and Petrology, 106(3): 379-397.

Nakamura, N. 1974. Determination of REE, Ba, Fe, Mg, $\mathrm{Na}$, and $\mathrm{K}$ in carbonaceous and ordinary chondrites. Geochimica et Cosmochimica Acta, 38: 757-775.

Nardi, L.V.S. 1991. Caracterização petrográfica e geoquímica dos granitos metaluminosos da associação alcalina: revisão. Pesquisas, 18(1): 44-57.

Nardi, L.V.S. \& Bitencourt, M.F.S. 2009. A-type granitic rocks in post-collisional settings in southernmost Brazil: their classification and relationship with tectonics and magmatic series. Canadian Mineralogist, 47(6): 1493-1503.

Nardi, L.V.S. \& Bonin, B. 1991. Post-orogenic and non-orogenic alkaline granite associations: the Saibro intrusive suite, southern Brazil - A case study. Chemical Geology, 92: 197-212.

Nardi, L.V.S. \& Lima, E.F. 2000.0 magmatismo Shoshonítico e Alcalino da Bacia do Camaquã - RS. In: Holz, M. \& De Ros, L.F. (Eds.), Geologia do Rio Grande do Sul. Porto Alegre, CIGO/ UFRGS. p. 119-131.

Paim, P.S.G., Chemale Jr., F. \& Lopes, R.C. 2000. A Bacia do Camaquã. In: De Ros L.F., Holz M. (Eds.). Geologia do Rio Grande do Sul. Porto Alegre, CIGO/UFRGS, p. 231-374.

Pearce, J.A., Harris, N.B.W. \& Tindle, A.G. 1984. Trace element discrimination diagrams for the tectonic interpretation of granitic rocks. Journal of Petrology, 25: 956-983.

Philipp, R.P. \& Machado, R. 2005. The Late Neoproterozoic granitoid magmatism of the Pelotas Batholith, southern Brazil. Journal of South American Earth Sciences, 19: 461-478.

Philipp, R.P., Machado, R. \& Chemale Jr., F. 2007. Geração dos granitóides Neoproterozoicos doBatólito Pelotas: evidências da composição isotópica de $\mathrm{Nd}$ e Sr e implicações para o crescimento continental da porção sul do Brasil. In: Iannuzzi, R. \& Frantz, J.C. 
(eds.), 50 Anos de Geologia. Instituto de Geociências. Contribuições. Porto Alegre, Comunicação e Identidade, p.59-77.

Porcher, C.A., Leite, S.R., Ramgrab, G.E.\& Camozzato, E. 1995. Mapeamento Geológico da Folha Passo do Salsinho, 1:50.000. Programa de Levantamentos Geológicos/Metalogenéticos Básicos do Brasil (PLGB). CPRM, Sureg-PA.

Ribeiro, M. \& Fantinel, L.M. 1978. Associações petrotectônicas do Escudo Sul-Rio-Grandense: I Tabulação e distribuição das associações petrotectônicas do Escudo do Rio Grande do Sul. Iheringia, Série Geológica, 5: 19-54.

Ribeiro, M., Bocchi, P.R., Figueiredo Foo., P.M. \& Tessari, R.I. 1966. Geologia da Quadrícula de Caçapava do Sul, RS. Rio de Janeiro, DNPM/DFPM, 232p. (Boletim 127).

Roisenberg, A., Formoso, M.L., Vieira Jr., N., Dutra, C.V., Altamirano, J.A.F. \& Ferreira, A.C. 1986. Petrologia e geoquímica do vulcanismo Proterozoico Superior-Eo-paleozoico do Escudo Sul-rio-grandense: Serrinha Tupanci e Cerro dos Lopes. In: CONGRESSO BRASILEIRO DE GEOLOGIA, 34, Goiânia, GO. Boletim de Resumos..., Goiânia, SBGE0, v. 1. p. 170.

Santos, R.V., Souza, P.A., Alvarenga, C.J.S., Dantas, E.L., Pimentel, M., Oliveira, C.G. \& Araújo, L.M. 2006. SHRIMP $\mathrm{U}-\mathrm{Pb}$ zircon dating and palynology of bentonitic layers from the Permian Irati Formation, Paraná Basin, Brazil. Gondwana Research, 9: 456-463.

Shellnutt, J.G., Wang, C.Y., Zhou, M.F. \& Yang, Y. 2009. Zircon Lu-Hf isotopic compositions of metaluminous and peralkaline A-type granitic plutons of the Emeishan large igneous province (SW China): constraints on the mantle source. Journal of Asian Earth Sciences, 35: 45-55.

Soliani Jr., E. 1986. Os dados geocronológicos do Escudo Sul-rio-grandense e suas implicações de ordem geotectônica. Tese de Doutoramento. Instituto de Geociências, Universidade de São Paulo, 425 p.

Soliani Jr, E., Koester, E. \& Fernandes, L.A.D. 2000. A geologia isotópica do Escudo Sul-rio-grandense - Parte I: métodos isotópicos e valor interpretativo. In: Holz, M. \& De Ros, L.F. (eds.). Geologia do Rio Grande do Sul, CIGO/UFRGS. Porto Alegre, p. 175-230.

Sommer, C.A., Lima, E.F. \& Nardi, L.V.S. 1999. Evolução do vulcanismo alcalino na porção sul do Platô do Taquarembó, Dom Pedrito - RS. Revista Brasileira de Geociências, 29(2): 245-254.

Sommer, C.A.; Lima, E.F.; Nardi, L.V.S.; Liz, J.D. \& Pierosan, R. 2003. Depósitos de fluxo piroclástico primários: caracterização e estudo de um caso no vulcanismo ácido neoproterozoico do Escudo Sul-Rio-grandense. Pesquisas em Geociências, 30(1): 3-26

Sommer, C.A., Lima, E.F., Nardi, L.V.S., Liz, J.D. \& Waichel, B.L. 2005a. The Neoproterozic Mildly Alkaline Bimodal Volcanism in Southern Brazil: Geological and Geochemical Aspects. International Geology Review, 47(10): 1090-1110.

Sommer, C.A., Lima, E.F., Nardi, L.V.S., Figueiredo, A.M.G. \& Pierosan, R. 2005b. Potassic and Low- and High-Ti Mildly Alkaline Volcanism in the Neoproterozoic Ramada Plateau, Southernmost Brazil. Journal of South American Earth Sciences, 18: 237-254.

Sommer, C.A., Lima, E.F., Nardi, L.V.S., Liz, J.D. \& Waichel, B.L. 2006. The evolution of Neoproterozoic magmatism in southernmost Brazil: shoshonitic, high-K tholeiitic and silica-saturated, sodic alkaline volcanism in post-collisional basins. Anais da Academia Brasileira de Ciências, 78: 573-589.

Whalen, J.B., Currie, K.L. \& Chappell, B.W. 1987. A-type granites: geochemical characteristics, discrimination and petrogenesis. Contributions to Mineralogy and Petrology, 95: 407-419.

Wildner, W. \& Nardi, L.V.S., 1999. Caracteristicas geoquímicas e petrogenéticas do vulcanismo neoproterozoico do sul do Brasil - Platô do Taquarembó - RS. In: SIMPÓSIO SOBRE VULCANISMO E AMBIENTES ASSOCIADOS, 1, Gramado. Boletim de resumos..., Gramado, SBGEO, v. 1, p. 30.

Wildner, W., Nardi, L.V.S. \& Lima, E.F. 1999. Post-collisional Alkaline Magmatism on the Taquarembó Plateau: a well Preserved Neoproterozoic-Cambrian Plutono-volcanic Association in Southern Brazil. International Geology Review, 41: 1082-1098.

Wildner, W., Lima, E.F., Nardi, L.V.S. \& Sommer, C.A. 2002. Volcanic cycles and setting in the Neoproterozoic III to Ordovician Camaquã Basin succession in southern Brazil: characteristics of post-collisional magmatism. Journal of Volcanology and Geothermal Research, 118: 261-283.

Winchester, J.A. \& Floyd, P.A. 1977.Geochemical discrimination of different magma series and their differentiation products using immobile elements. Chemical Geology, 20: 325-343.

Zerfass, H., Almeida, D.M.P. \& Gomes, C.H. 2000. Faciology of Acampamento Velho formation volcanic rocks (Camaquã Basin) in the region of Serra de Santa Bárbara, Cerro do Perau and Cerro do Bugio (Municipality of Caçapava do Sul - RS). Revista Brasileira de Geociências, 30: 12-16.
Manuscrito 524.

Editores: Edinei Koester e Paulo A. Souza. 